\title{
KIFC1 is essential for acrosome formation and nuclear shaping during spermiogenesis in the lobster Procambarus clarkii
}

\author{
Dan-Dan Ma' ${ }^{1}$, Lian Bi ${ }^{1}$, Wan-Xi Yang ${ }^{1}$ \\ ${ }^{1}$ The Sperm Laboratory, College of Life Sciences, Zhejiang University, Hangzhou, Zhejiang, China \\ Correspondence to: Wan-Xi Yang, email: wxyang@spermlab.org \\ Keywords: procambarus clarkii, spermiogenesis, KIFC1, microtubule, RNAi
}

Received: February 17, 2017

Accepted: March 14, 2017

Published: March 21, 2017

Copyright: Ma et al. This is an open-access article distributed under the terms of the Creative Commons Attribution License (CC-BY), which permits unrestricted use, distribution, and reproduction in any medium, provided the original author and source are credited.

\section{ABSTRACT}

In order to study the function of kinesin-14 motor protein KIFC1 during spermatogenesis of Procambarus clarkii, the full length of kifc1 was cloned from testes cDNA using Rapid-Amplification of cDNA Ends (RACE). The deduced KIFC1 protein sequence showed the highest similarity between Procambarus clarkii and Eriocheir senensis (similarity rate as 64\%). According to the results of in situ hybridization (ISH), the kifc1 mRNA was gathered in the acrosome location above nucleus in the mid- and late-stage spermatids. Immunofluorescence results were partly consistent with the ISH in middle spermatids, while in the late spermatids the KIFC1 was distributed around the nucleus which had large deformation and formed four to six nuclear arms. In the mature sperm, KIFC1 and microtubules were distributed around the sperm, playing a role in maintaining the sperm morphology and normal function. Overexpression of $P$. clarkii kifc1 in GC1 cells for 24 hours resulted in disorganization of microtubules which changed the cell morphology from circular and spherical into fusiform. In addition, the overexpression also resulted in triple centrosomes during mitosis which eventually led to cell apoptosis. RNAi experiments showed that decreased KIFC1 protein levels resulted in total inhibition of spermatogenesis, with only mature sperm found in the RNAi-testis, implying an indispensable role of KIFC1 during $P$. clarkii spermiogenesis.

\section{INTRODUCTION}

Kinesin is a superfamily of motor proteins that goes along the microtubule rails transporting cargoes. It often contains three domains, a conserved head including ATPbinding sequence and a microtubule-binding sequence, a curling stalk, and a variable globular tail. There are 14 families of kinesins according to the phylogenic results, among which only the kinesin-14 family contains $\mathrm{C}$-terminal motor that moves from the minus end of microtubules to the plus end $[1,2]$. The kinesin- 14 family member KIFC1, as a transport machine for the cargoes, is usually found to be working with microtubules and play a part in spermiogenesis of a myriad of species.

Spermiogenesis refers to terminal phase of spermatogenesis and includes the transformation of the spermatids into mature and fertile sperms. There are various reports illuminating the different roles of KIFC1 plays in different species during spermiogenesis. Firstly, it takes part in the transformation of the acrosome. It is one of the components of the temporary structure acroframosome (AFS) that works as the scaffold for acrosome building in the Crustacea, Natantia such as Expolaemon modestus and Macrobrachium nipponense $[3,4]$. It also takes part in the formation and maintenance of the Eriocheir sinensis acrosome structure [5]. Secondly, it participated in the nuclear morphogenesis. KIFC1 presents in the formation of manchette-like structure in the Octopus tankahkeei, presuming to constrain nucleus via mechanical force generated by its movement on the manchette microtubules [6]. For Sepiella maindroni, the expression of kifcl increased where and when the nuclei are changing [7]. It is also conjectured to participate in the formation of sperm head and tail in Eumeces chinensis [8].

There is no research of KIFC1 so far focusing on the Macrura, Crustacea, Reptantia. Red swamp lobster (Procambarus clarkii), the invasive species all around the world similar to the rusty crayfish (Orconectes rusticus) in the US [9] is a good example of Reptantia. On one side, such an invasive animal causes ecological damage to local species [10]. On the other side, the crayfish is becoming popular food in China for its palatable taste thus catalyzes the 
emergence of farms. Thus, the research of its reproduction is a guidance for controlling the population of the species.

In mammals, spermiogenesis is divided into four steps for the change of nuclei and acrosome [11]. As for $P$. clarkii, the most important changes during spermiogenesis include the formation of a modified nucleus with which to transmit genetic information and an acrosome presumably for effecting fertilization. Our experiment would focus on three questions: Firstly, Does Reptantia have the same structure of acroframosome as the Natantia? Secondly, is KIFC1 relative to the nuclei reshaping? Thirdly, does the KIFC1 participate in the formation of acrosome? In order to answer these questions, we cloned the full length of kifcl in P. clarkii in the testes and studied its expression pattern during the spermiogenesis using both the RNA probe as well as its antibody. Overexpression in cultured cells as well as RNAi were further used to clarify its functions during spermiogenesis. Our results will provide some evidence for the KIFC1 functions relating to the sperm maturation of crustaceans.

\section{RESULTS}

\section{The spermiogenesis of $P$. clarkii}

There are three testes in $P$. clarkii that were located within the head cuirass, under the pericardial cavity and over the hepatopancreas. The testes were in ellipsoid or long capsule form. Inside the testes there existed different develop stages between senimiferous tubules. The spermiogenesis was divided into four stages according to the different spermatid morphology, which could be distinguished by their sizes and nuclear shapes (Figure 1). The spermatocyte has clear bounder of nucleus and cytoplasm, the chromatin was loosely distributed in the circular nucleus (Figure 1A). In early-stage spermatids the nucleus shrinks into a short rod-like shape and increases in density with small snacks of annulate lamellaes (Figure 1B). In the mid-satge spermatids the nucleus continues to change forming a bone-like shape with a large vesicle (pro-acrosome) lining proximal to the nucleus (Figure 1C). In the late-stage the spermatids are pro-mature, the nucleus extends into four to six arms with a deep invagination in the side of acrosome complex (Figure 1D). The mature sperm is a non-motile flattened spheroid that has a highly condensed nucleus with the arms wrapped around its body and a globate cup-shaped acrosome complex (Figure 1E).

\section{Full length of $P$. clarkii kifc1}

The full length of $P$. clarkii-kifcl is $2499 \mathrm{bp}$ in length (GenBank accession number: KM099199). It contains 143 bp 5' untranslated region (UTR) and 160 bp 3' UTR. The translated region is a 2193 bp open reading frame (ORF),
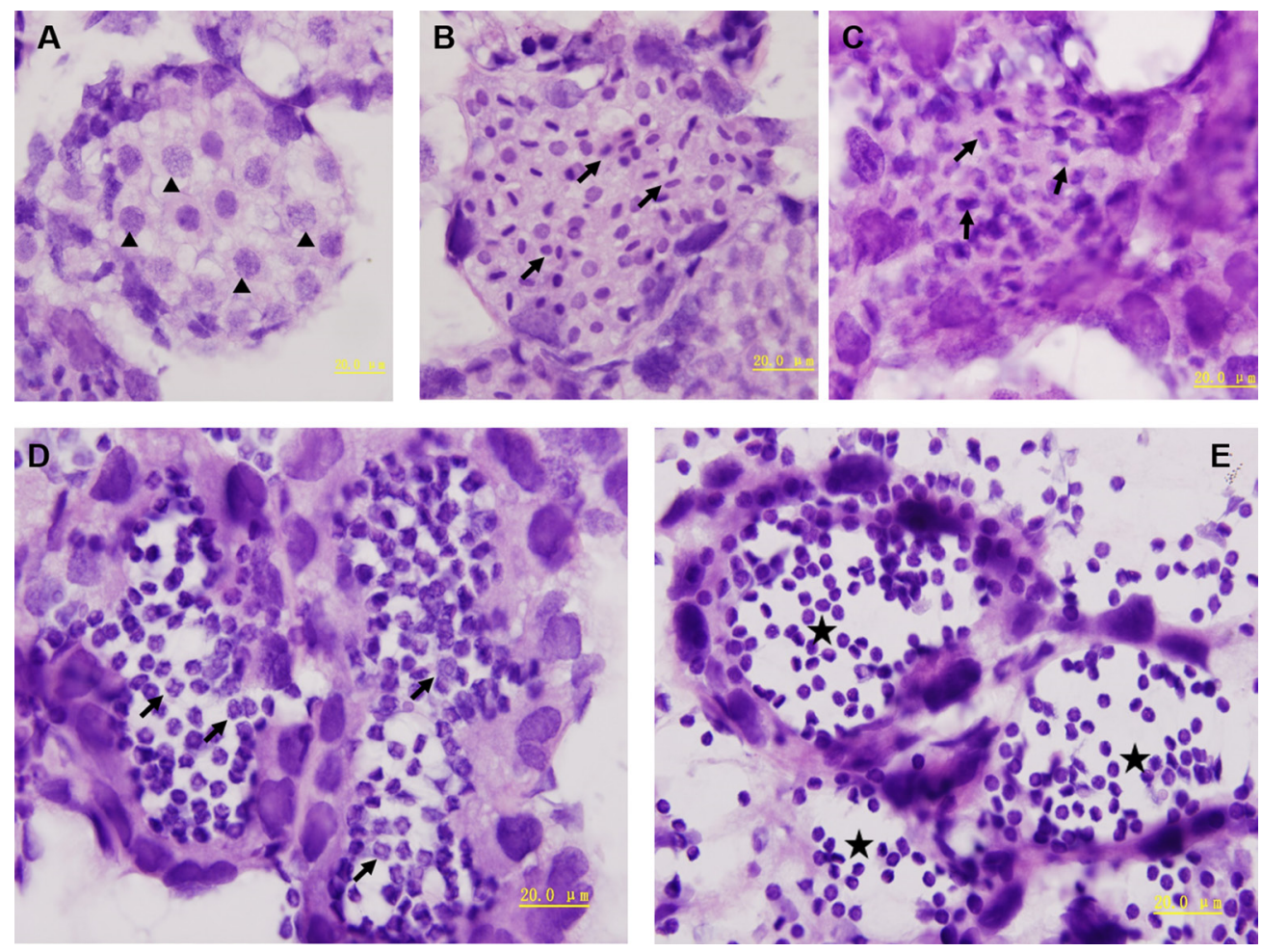

Figure 1: The spermiogenesis of $\boldsymbol{P}$. clarkii. The spermatocytes were the largest among spermatogenic cells, the nucleus was big and round (A, arrow heads). The spermatids were much smaller than spermatocytes (B-D). In the early-stage spermatids, the nucleus shrinks into a short rod-like shape and increases in density (B, arrows). In the mid-stage spermatids, the nucleus continues to shrink into bone-like shape $(\mathrm{C}$, arrows). In the late-stage spermatids, the nucleus extends into four to six arms (D, arrows). The mature sperm is the smallest cells in testes that had a condensed nucleus with the arms wrapped around its body (E, stars). 
encoding 731 amino acids of which the predicted molecular weight is $81 \mathrm{kDa}$ (Figure 2, Supplementary Figure 1).

\section{The phylogenetic analysis of KIFC1 and putative protein analysis}

Using the amino acid sequence of $P$. clarkii, the phylogenetic tree was analyzed by Mega 6.0. We compared P. clarkii KIFC1 sequence with that of Mus musculus, Homo sapiens, Danio rerio, Plestiodon chinensis, Sepiella maindroni, Exopalaemon modestus, Macrobrachium nipponense, Eriocheir sinensis. It was found that the $\mathrm{KIFC1}$ is more similar to its Reptantia cousin, Eriocheir sinensis. The similarity rate was as high as $64 \%$ shown by NCBI blast results (Figure 3A).

We used I-TASSER to predict the three structural domains of KIFC1. The predict model of the KIFC1 protein consists of a typical C-terminal Kif head that walks along the microtubules, a $\mathrm{N}$-terminus tail that carries specific cargoes and a helix stalk region that link the two domains (Figure 3B).

\section{The kifcl mRNA expression levels among $P$. clarkii tissues}

The analysis of relative content in Figure 4 demonstrated that kifcl is highly expressed in circulatory system (heart), excretory system (green gland), and reproductive system (testis). Very weak expression of kifcl was detected in the muscle and gill.

\section{The KIFC1 protein expression levels among $P$. clarkii tissues}

The Exopalaemon modestus polyclonal KIFC1 antibody was proved to be capable for P. clarkii-KIFC1 to get single, distinct and valid bands (Supplementary Figure 2). We compared the KIFC1 protein amount between testis and heart, muscle and green gland using $\beta$-actin as control. The expression of KIFC1 was higher in testis and heart than muscle and green gland (Figure 5).

\section{The kifcl mRNA expression pattern during $P$. clarkii spermiogenesis}

We used the anti-sense DIG-labelled kifcl probe to detect the kifcl mRNA spatial and temporal expression pattern in testes. In the spermatocytes, the kifcl was randomly distributed in the cytoplasm (Figure 6A, a), then the kifcl was highly transcribed and distributed both in nucleus and cytoplasm in early spermatids (Figure 6B, b). The kifcl signals was then gathered in the acrosome location above nucleus, rendering cargo transport along microtubule during acrosome formation in the mid-stage (Figure 6C, c) and late-stage spermatids (Figure 6D, d). With the reduced whole sperm gene transcriptional level as a result of highly condensed nuclear materials the kifcl mRNA was also low expressed in mature sperm (Figure 6E). The control slides incubated with sense kifcl probe showed no signal (Figure 6F).

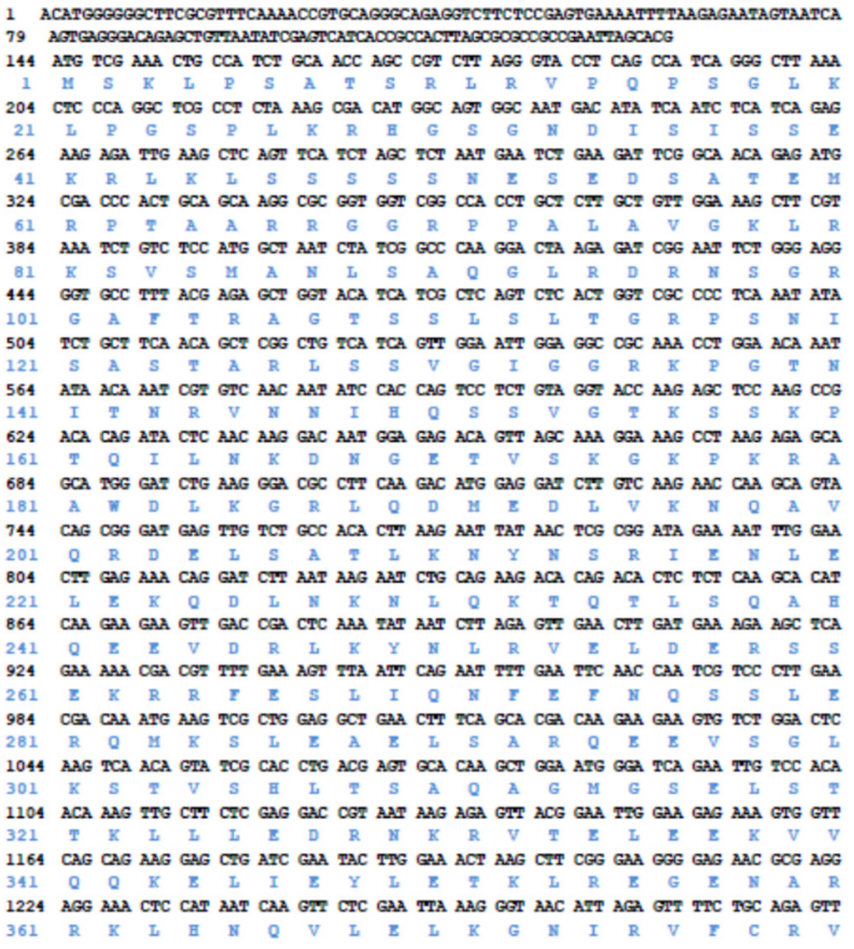

1284 CGI COC TTG ATT GGA GAC GAG CGN AAG AAC AAC GOC CAT TCA GAY GTA GIT CAT CAT ATA

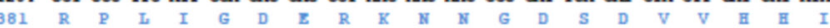

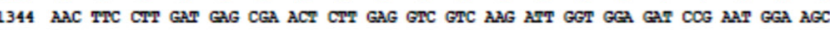

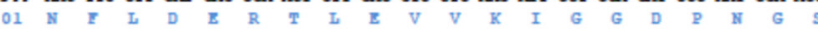
1404 ACA ATG TCT GOC CTG AAA GE COI GGA AAT GGC GOC ITI GAA TIC TCG TIT GAT CGA GTC

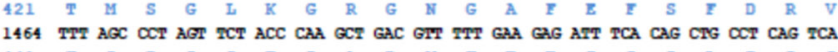

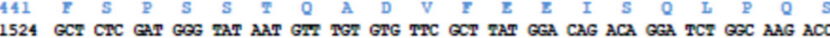

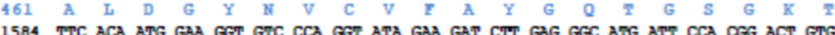

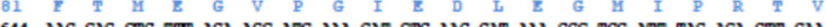
1644 AAG CAC CIG TIT NGA ACC ANG AAA GAT CTG AAG GAT AAA GEC TGG ATP TAC ACA GTT GA 1704 GCA AGC TTP CTA EAG ATT TAY AAC GAA ACC ATP AOG EAT CTT CTP GCC TCT TCC AAA GAC

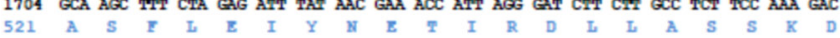
1764 TCC AAA AGT CTI ACC TAC GAA ATR AAA TTG ACT GAC AGC AAA AAG AAF GAA ACC TTP GTG

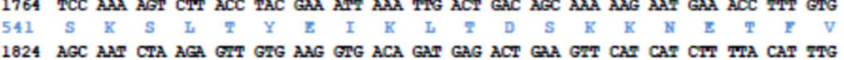

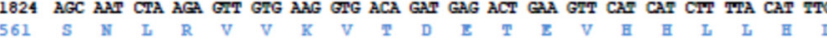

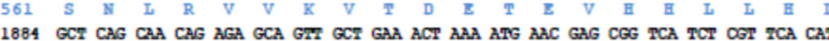

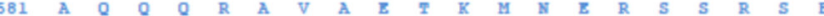
1944 TCC GNC TTC CGI TIG AAA CII GIG GGI TCA AAC AOC AIT ACA TCI GAA TOG TOT GAG GEC

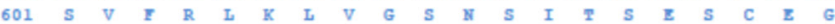
2004 ACA CTC AAT CTC GIG GAC CTG GCI GGC TOG GAG COC CTG AAG GAA TCC GGC TCA GAA GES 521 T I I V D I A G S E R L K E S G S E G 2064 GCC AGG TTG ACA GAG ACG CAG AAT ATC AMT AAG TCT CTC TCA AMP CTP GGG AAT GTA ATA 541 A $R$ R 2124 ATG GCA TTG GGA CAG AAG CAA AGC TTP ATT COG TAT CEA AAT TCC AAG CNG ACG CAT GTG

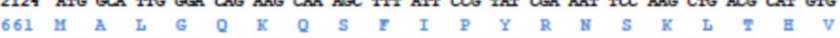
2184 TTG CAA AGC TOG CTT GGT GGI AAC TCG ACG ACA CTG ATG TIT GIC AAC GTT TCG COG CTG 681 L 2244 GAG ANG TGP TTC AAC GAG ACA CTA AAI TCA CTC COG TIT GCC ACC AAA GIY AAC CAG TGP

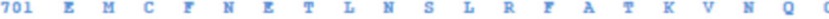
2304 CAR ATP GGC ACA GCA ADG AAG CAG GIT ACA AAA TAA

2340 AGAGCAAATGPACAGTACAGPATATGRATCTrGPAAMTATCITCAGMGTACrTAGCCATATATTCAAAATTAATAGP

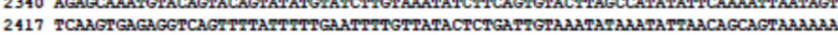
2494 ААAAMA

Figure 2: The full cDNA length of $\boldsymbol{P}$. clarkii kifc1 gene. The kifcl includes a 143 bp 5' UTR, 160 bp 3' UTR and a 2193 bp ORF encoding 731 amino acid. 


\section{The KIFC1 protein expression pattern during P. clarkii spermiogenesis}

In the spermatocytes, the microtubules and KIFC1 were randomly dispersed and co-localized in the cytoplasm (Figure 7). In the early-stage spermatids, the microtubules started to gather in one side of the nucleus where the proacrosomal granules were formed, forming an umbrellashaped structure (Figure 8), the KIFC1 signals were dispersed in the cytoplasm (Figure 8). In the mid-stage of spermiogenesis, the microtubules and KIFC1 were colocalized at one side of the reshaping nucleus of the midstage spermatids (Figure 9). During late spermiogenesis, the nucleus underwent dramatic morphological changes and formed 4-6 nuclear arms. It was found that KIFC1 as well as microtubules surrounded the changing nucleus of the late spermatids (Figure 10). KIFC1 and microtubules was located around the whole mature sperm and may be a support for the cellular structure (Figure 11).

\section{Effects of $P$. clarkii KIFC1 overexpression on GC1 cells}

24 hours after transfection, the GC1 cells of control groups (transfected with pCMV-N-Flag) were circular or oval with microtubules dispersed around the nucleus (Figure 12D). However, in the experimental groups (transfected with pCMV-N-Flag- $P$. clarkii kifcl), the microtubules were irregularly arranged (Figure 12F) which eventually changed the cell and nuclear shape from circular and oval to fusiform (Figure 12E, 12H).

In addition to that, the $\mathrm{GC} 1$ cells in control groups displayed normal mitosis, which formed two spindle poles that separated the chromosome evenly into two daughter
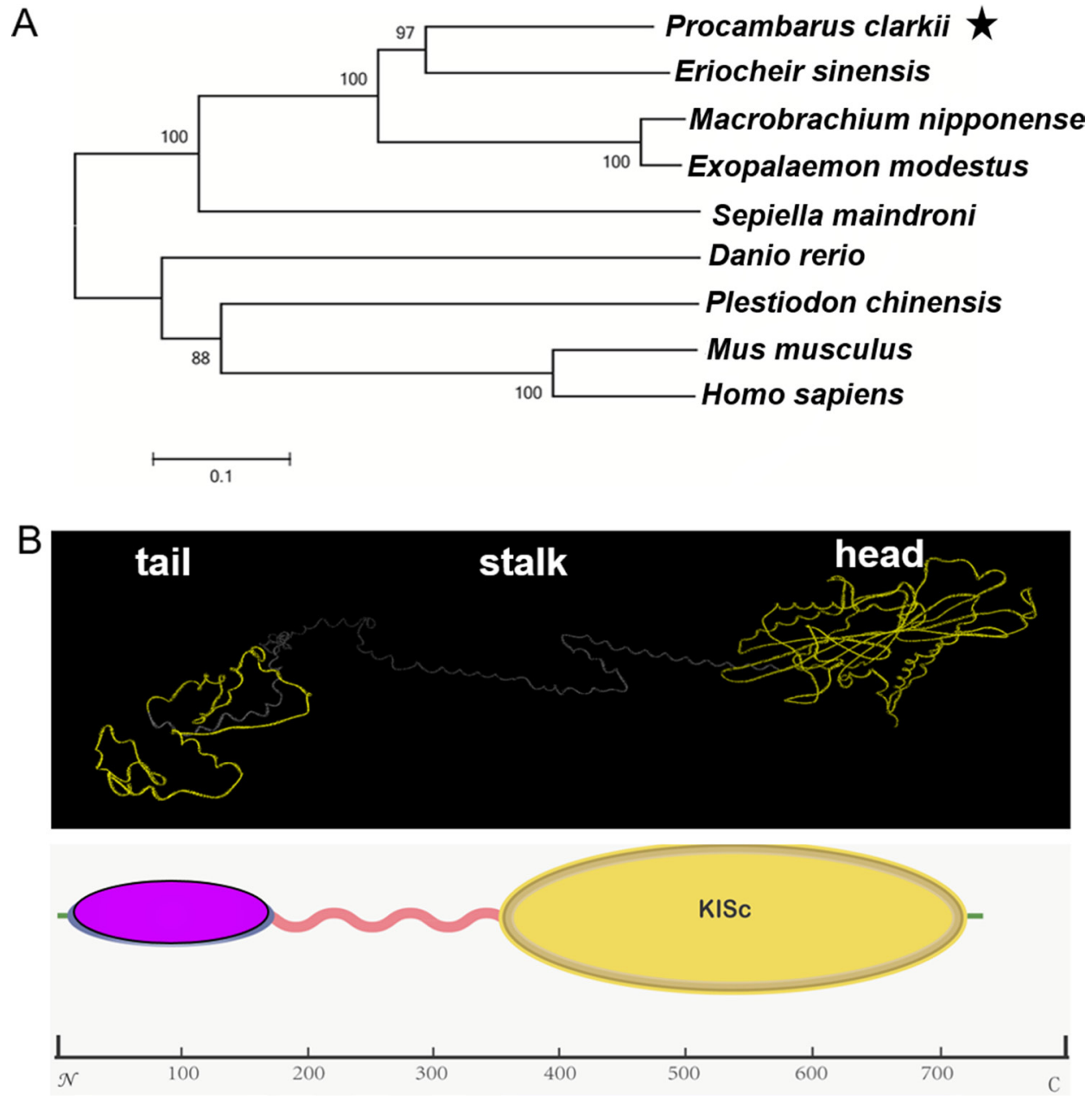

Figure 3: The phylogenetic analysis of KIFC1 and putative protein analysis. Using the amino acid sequence of $P$. clarkii, the phylogenetic tree was analyzed using Mega 6.0, comparing KIFC1 homologues among various species including Mus musculus (uniprot: Q9QWT9), Homo sapiens (uniprot: Q9BW19), Danio rerio (uniprot: Q7ZZ74), Plestiodon chinensis (uniprot: A0A067XH81), Sepiella maindroni (uniprot: U5HTJ7), Exopalaemon modestus (uniprot: A0A088MIU8), Macrobrachium nipponense (uniprot: U5HTJ1), Eriocheir sinensis (uniprot: D9DBK9). The KIFC1 is more similar to its Reptantia cousin, Eriocheir sinensis (A). The C-terminus contains the conserved head (the yellow ball) that walks along the microtubules. The stalk region forms a helix region. The N-terminus contains the tail domain (the pink ball) that carries various cargoes, as predicted by I-TASSER (B). 
cells (Figure 13B, 13D). In the experimental groups there exist a portion of cells that exhibited abnormal mitosis, forming three spindle poles that separated the chromosome into three partitions and eventually drove the cells into apoptosis (Figure 13F, 13H).

\section{Effects of KIFC1 knockdown on P. clarkii testes}

The efficiency of kifcl-siRNAs were examined in vitro using GC1 cells. It was found that all three siRNAs had a knockdown effect on the KIFC1 expression, the siRNA3 being the most effective siRNA which had a reduction of $81.4 \%$ over $60 \%$ of the samples (Supplementary Figure 3).

The siRNA3 also had a knockdown effect of more than $70 \%$ in testes in vivo. 3 days after injection, the testes of blank groups (injected with PBS) showed high expression of KIFC1 (Figure 14C1) and microtubules (Figure 14B1) and normal morphology containing spermatocytes (Figure 14A1a), various stages of spermatids (Figure 14A1 b\&c) and mature sperm (Figure 14 A1e), as showed by the nuclear shapes. High

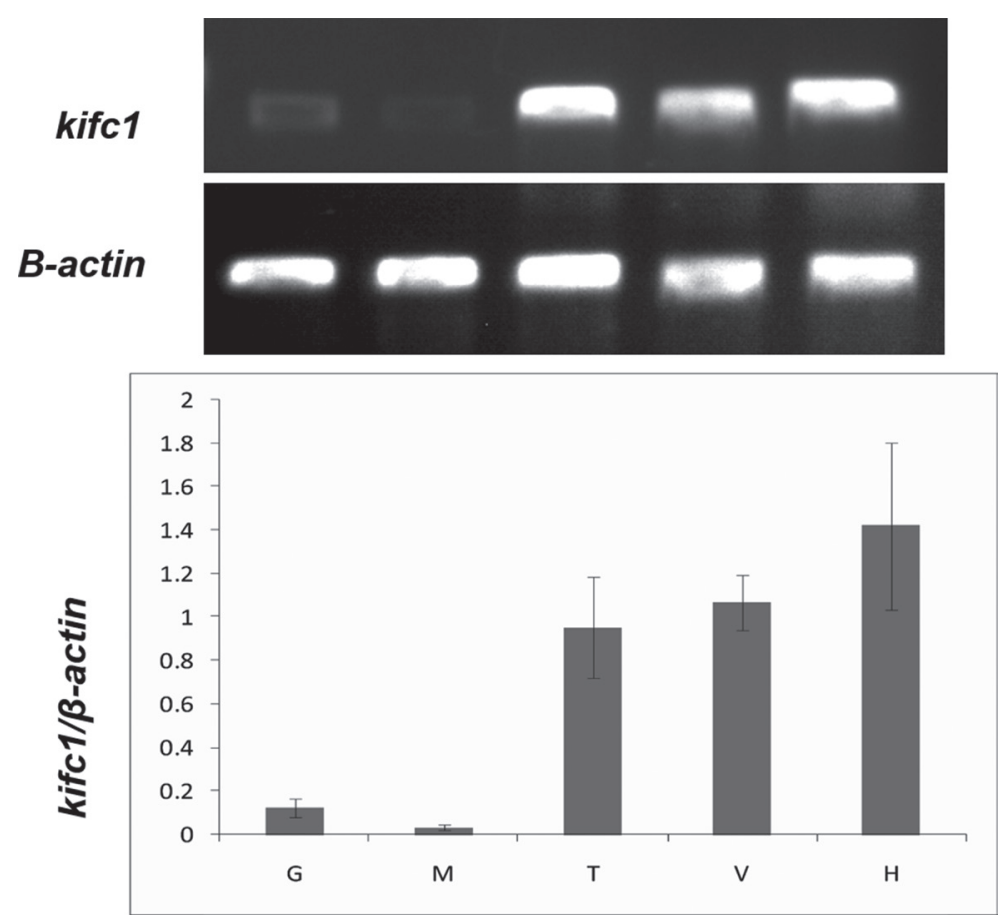

Figure 4: Semi-quantitative RT-PCR analysis of kifcl $\mathbf{m R N A}$ levels among different tissues. $\beta$-actin was used as a positive control (lower panel). G. gills, M. muscle, T. testis, V. green glands, H. heart.

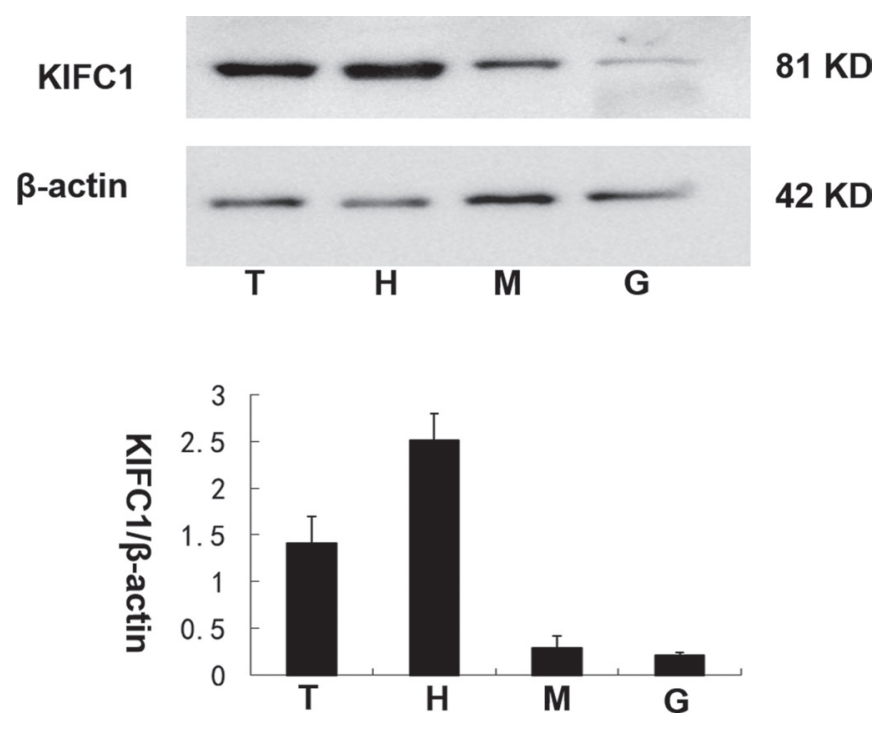

Figure 5: The KIFC1 protein expression levels among $P$. clarkii tissues. KIFC1 was highly expressed in testis and heart while relatively low in muscle and green gland. $\beta$-actin was used as a positive control. T. testis, H. heart, M. muscle, G. green gland. 
expression of KIFC1 and microtubules were detected in the testes of the negative and blank groups (Figure 14B1B3). In the experimental groups, the sizes of testes were a bit smaller than the control groups, the expression levels of KIFC1 and microtubules were significantly reduced (Figure 14 C2\&3), spermatocytes and different stages of spermatids were not found, and only mature sperm were observed in the kifcl-siRNA groups (Figure 14 A3e). After 9 days of injection, the amount of mature sperm was also significantly reduced in kifcl-siRNA groups (data not shown).

\section{DISCUSSION}

Freshwater crayfish as the world's third largest crustacean species, is a significant worldwide aquatic food with a long history of human consumption [12]. Studies on
P. clarkii mainly focused on toxicology $[13,14]$, ecology [15], neuron and behavior [16, 17], nevertheless their reproduction mechanism and regulation remain much unknown. Our previous work on $P$. clarkii investigated the mitochondrial prohibitin and its ubiquitination during crayfish spermiogenesis [18]. In this paper we studied the function of cytoskeletal microtubules and motor protein KIFC1 in the spermiogenesis of $P$. clarkii.

\section{Expression of KIFC1 in P. clarkii tissues}

The kinesin 14 protein KIFC1, which is homologous to human HSET [19], Xenopus XCTK2 [20], Drosophila Ncd [21] and yeast Kar3 [22], is reported to be an ancient protein and played a role in various species. The three dimensional analysis of $P$. clarkii KIFC1 protein shows a 350-residue C-terminal globular motor domain that is
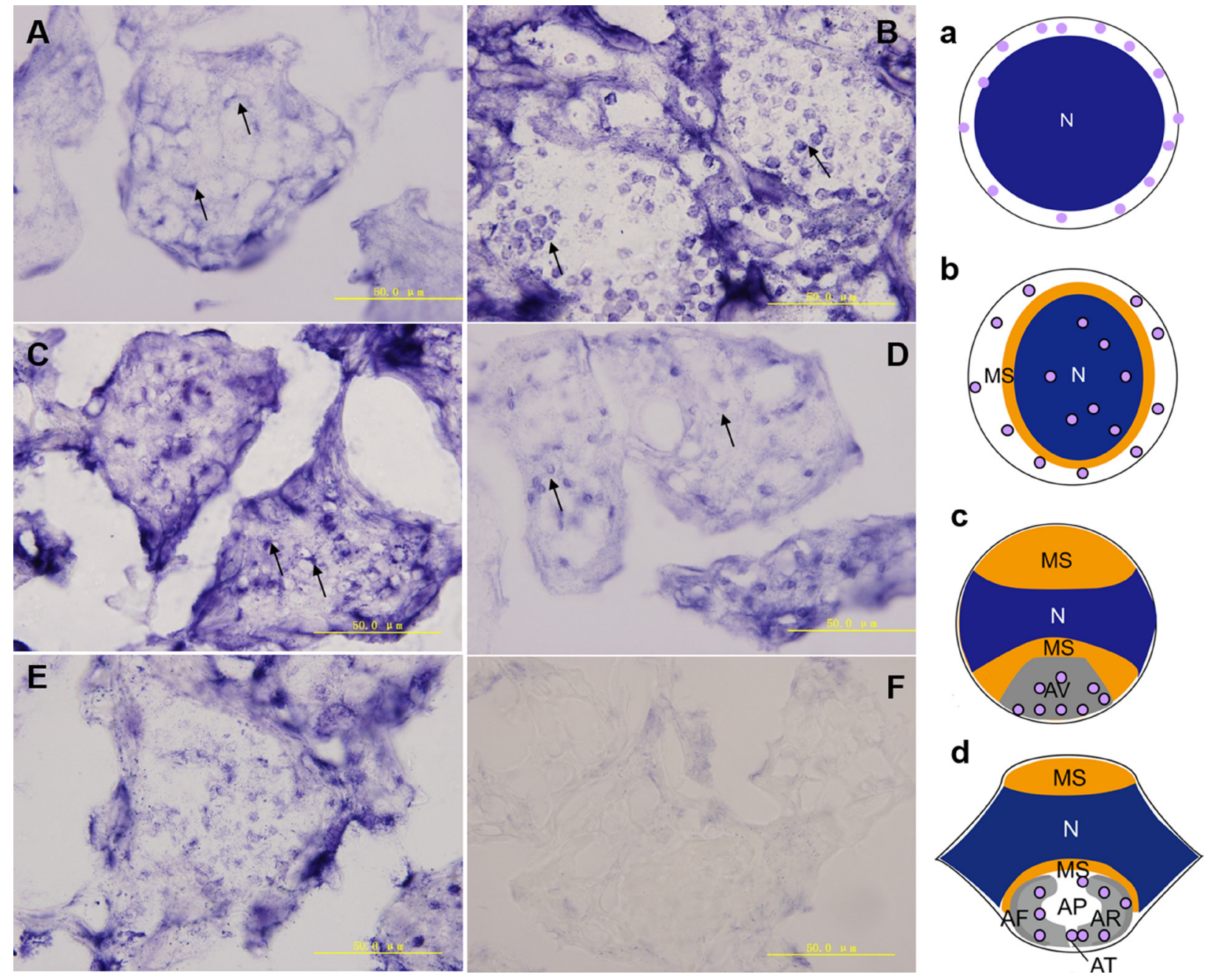

Figure 6: The kifcl mRNA expression pattern during $\boldsymbol{P}$. clarkii spermiogenesis. (A-E) In the spermatocytes, kifcl was randomly distributed in the cytoplasm (A, arrows). In early-stage spermatids, kifcl was highly transcribed and distributed in cytoplasm as well as nucleus (B, arrows). In the mid-stage spermatids, kifcl signals were gathered in the AV of acrosome location (C, arrows). In the latestage spermatids, kifcl signals were gathered in the AF and AR of acrosome location (D, arrows). The kifcl mRNA was lowly expressed in mature sperm (E). The control slides incubated with sense kifcl probe showed no signal (F). N. nucleus, MS. membrane sheets, AV. acrosomal granule, AF. acrosomal filament, AR. acrosomal cap, AP. cloudy material in acrosomal cap, AT. acrosomal tubules. a-d. models of kifcl expression of A-D. 
conserved in the kinesin family [23], N-terminal species specific cargo binding domain that is slightly longer than that of other crustaceans, and a helical neck region that links these two domains. KIFC1 has been shown to participate in chromosomal and spindle movement during mitosis and meiosis, and transport membranous organelles and macromolecules fundamental to cellular functions [24]. It was found that kifcl mRNA was expressed in varieties of tissues in P. clarkii including testis, heart, green gland, muscle and gill, implying a wide function in $P$. clarkii, although there existed a difference in kifcl levels among tissues, with higher expressions in testis, heart, green gland while a relatively lower expressions in muscle and gill. The Western blot results were consistent with the semi-quantitative results and showed that KIFC1 protein was highly expressed in $P$. clarkii testes compared with other tissues. In this paper we focused on the KIFC1 function in spermiogenesis of $P$. clarkii, in order to shed a light on the reproduction mechanism and regulation.

\section{KIFC1 participates in $P$. clarkii acrosome biogenesis}

According to Moses (1961) who observed the structural characterization of $P$. clarkii spermiogenesis by transmission electron microscope (TEM), the aflagellate sperm of $P$. clarkii can be homologized to flagellate forms only to the extent that both contain a modified nucleus with which to transmit genetic information and an acrosome presumably for effecting fertilization [25]. While the small snacks of annulate lamellaes formed during the middle spermatids which later turned into the PAF-positive acrosome complex, it drew our attention that how the protein and carbohydrate moieties move, arrange and organize into the functional and indispensable acrosome. It is clear that cells use a number of KIFs and tightly controls the direction, destination, and velocity of transport of various important functional molecules $[26,27]$, the C-terminal motor protein KIFC1 was supposed to have played a role in spermiogenesis of $P$. clarkii. The ISH results showed that the kifcl mRNA was primarily dispersed in the cytoplasm of early-stage spermatids, then gathered in the location where acrosome was formed in middle and late spermatids. The IF results also showed that, during acrosome formation the KIFC1 protein accumulated at one pole of the nucleus together with microtubules. Our previous studies on E. modestus [3] and M. nipponense [4] discovered that microtubules formed an umbrella-shaped structure over the nucleus (named acroframosome, AFS) during spermiogenesis, which was assumed to work as a scaffold for the kinesins and dyneins to transport cargoes that later were organized
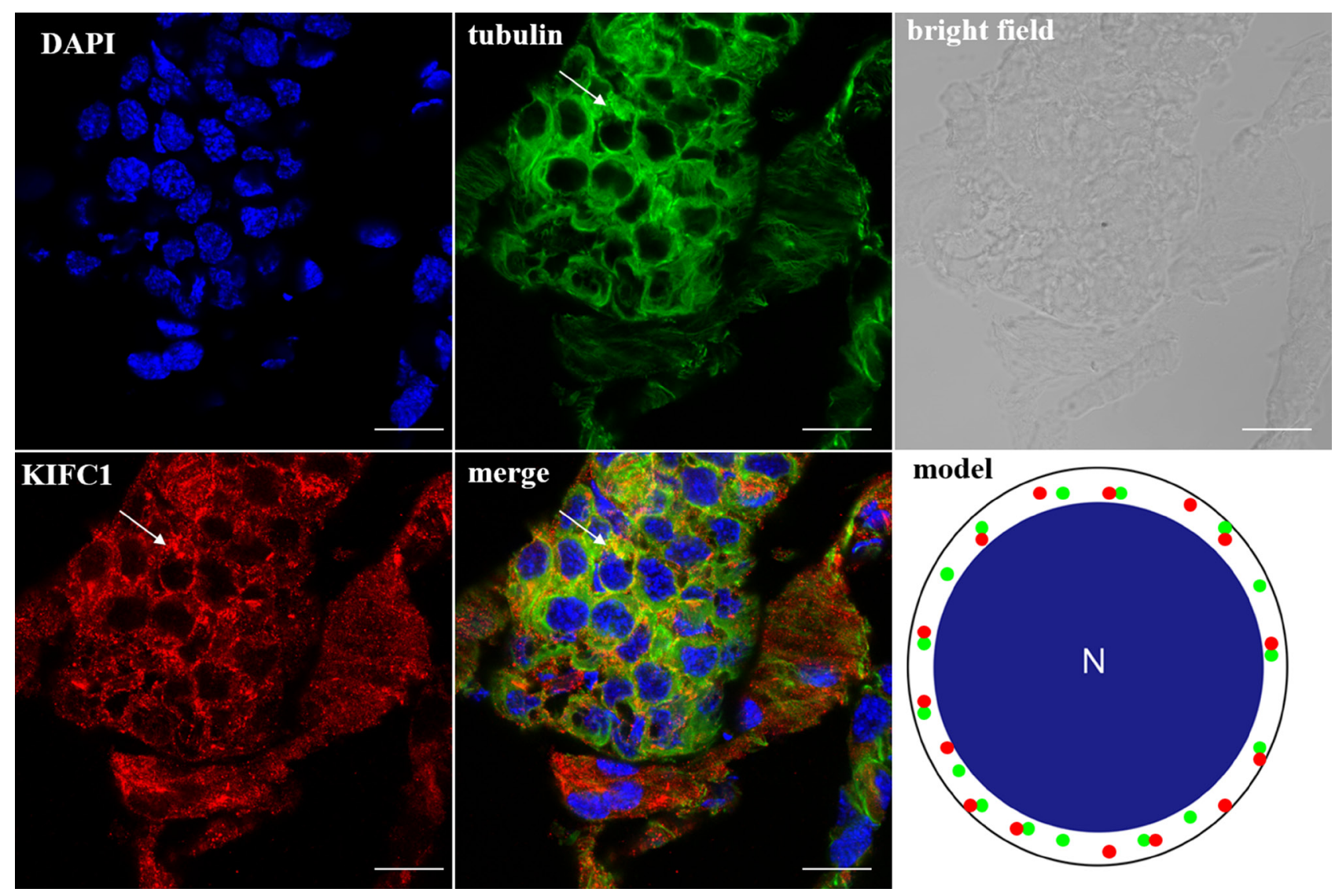

Figure 7: KIFC1 and microtubule expression pattern in spermatocytes. KIFC1 and microtubules were randomly dispersed in the cytoplasm (arrows). Red: KIFC1. green: microtubules. blue: DAPI labeled nucleus. N. nucleus. $($ bar $=10 \mu \mathrm{m})$. 


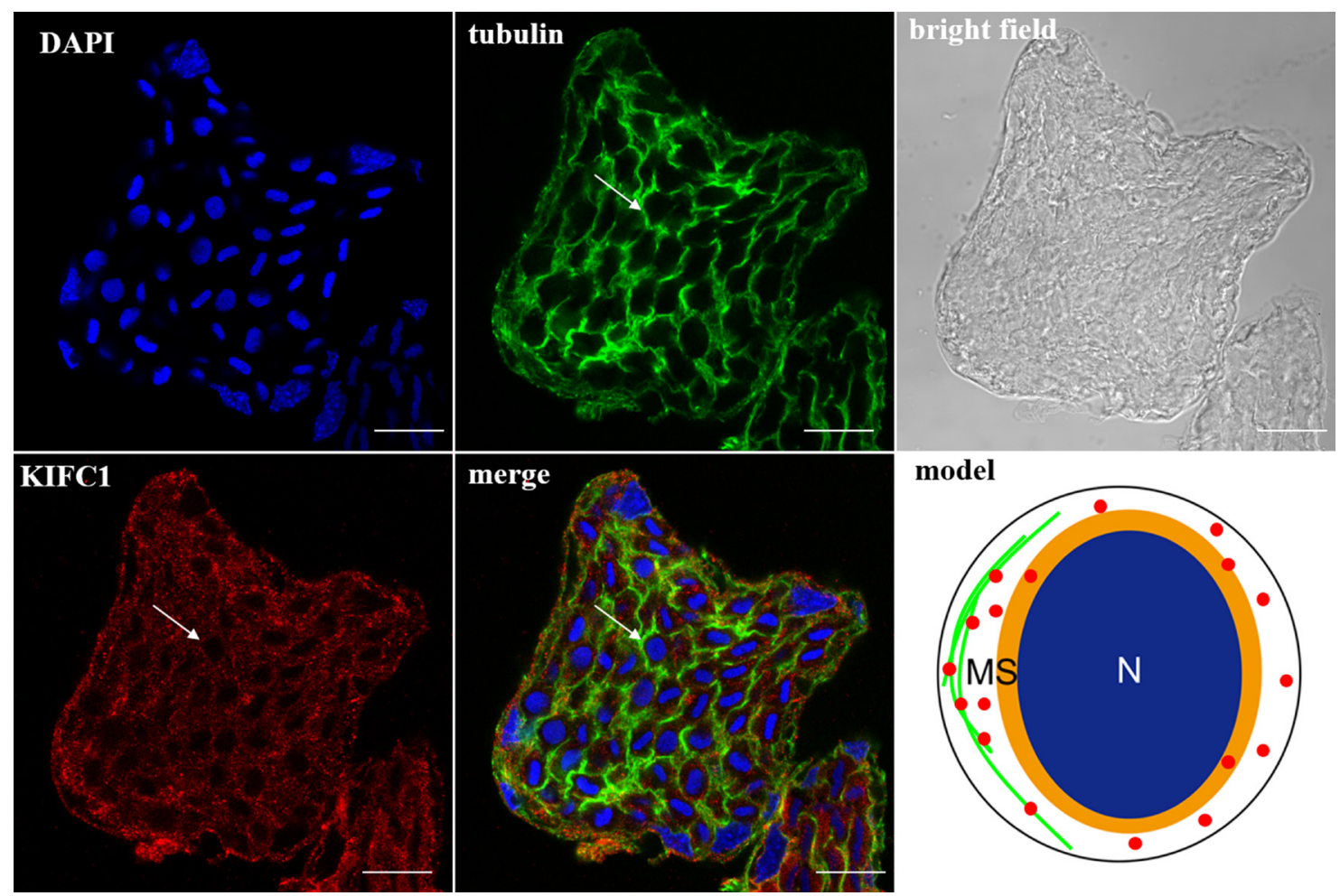

Figure 8: KIFC1 and microtubule expression pattern in early-stage spermatid. The microtubules began to gather on one side of nucleus (tubulin, arrow). KIFC1 was dispersed in the cytoplasm (KIFC1, arrow). Red: KIFC1. green: microtubules. blue: DAPI labeled nucleus. N. nucleus, MS. membrane sheets. $($ bar $=10 \mu \mathrm{m})$
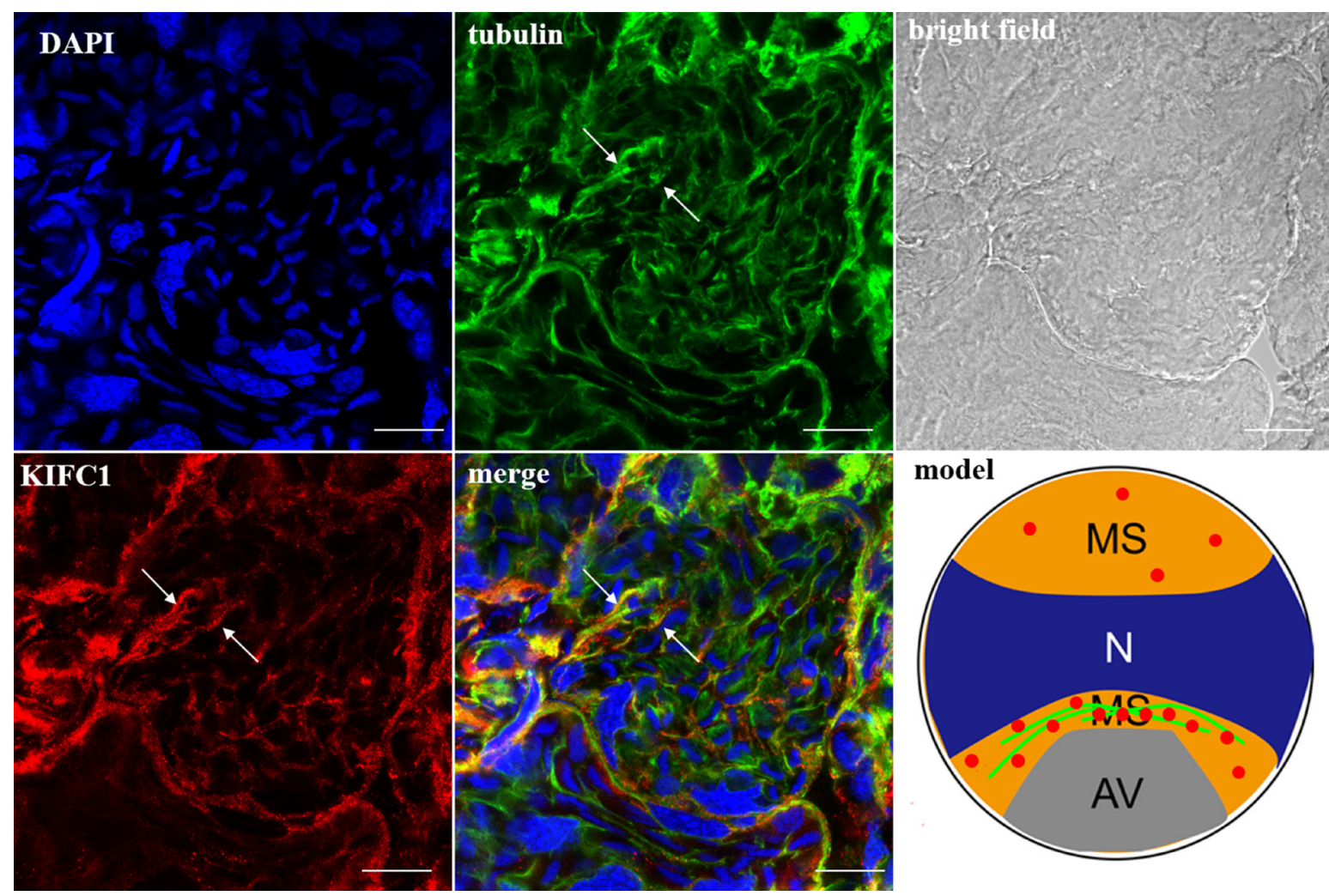

Figure 9: KIFC1 and microtubule expression pattern in mid-stage spermatids. The microtubules and KIFC1 were colocalized at one side of the reshaping nucleus (merge, arrows). Red: KIFC1. green: microtubules. blue: DAPI labeled nucleus. N. nucleus, MS. membrane sheets, AV. acrosomal granule. (bar $=10 \mu \mathrm{m})$ 

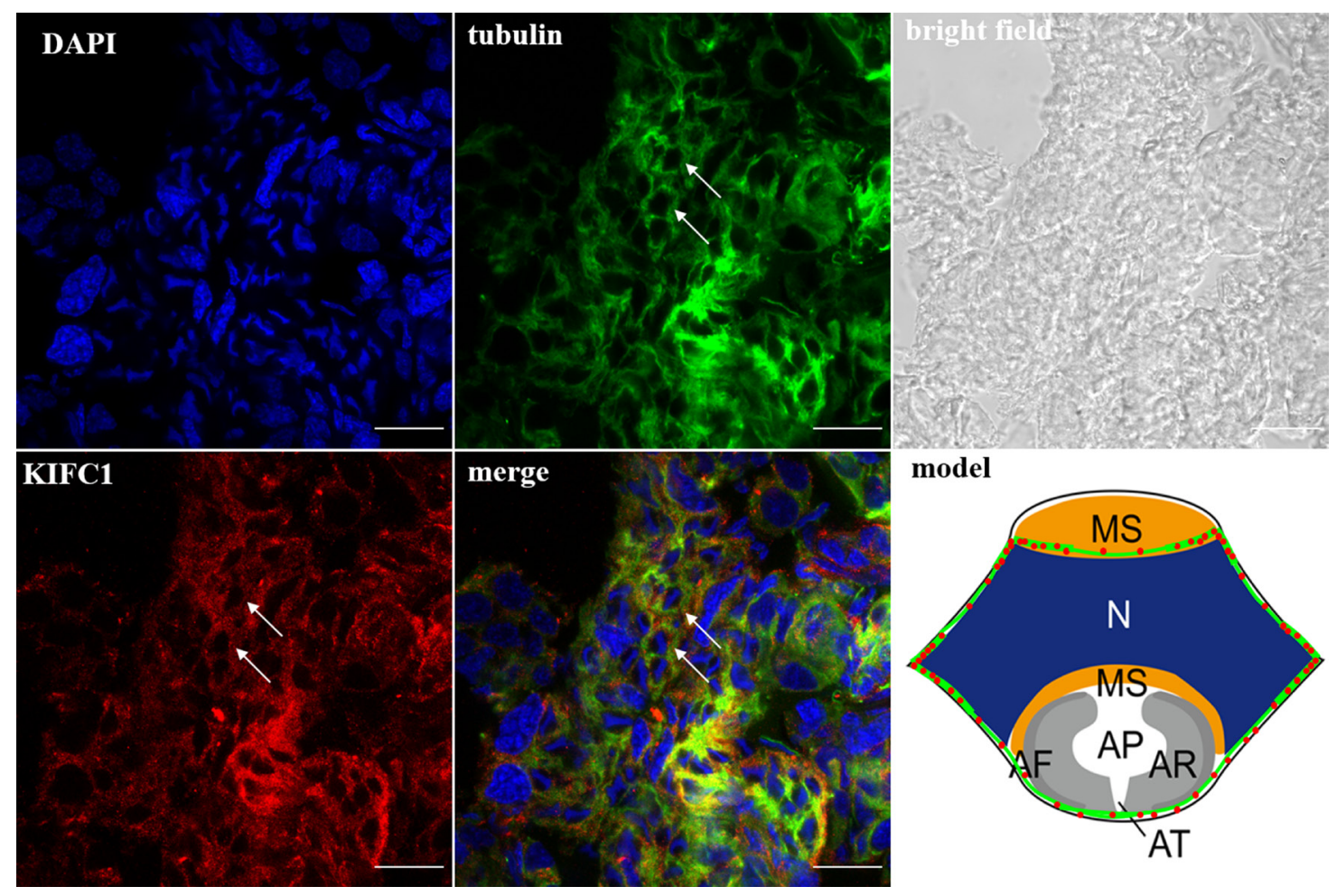

model

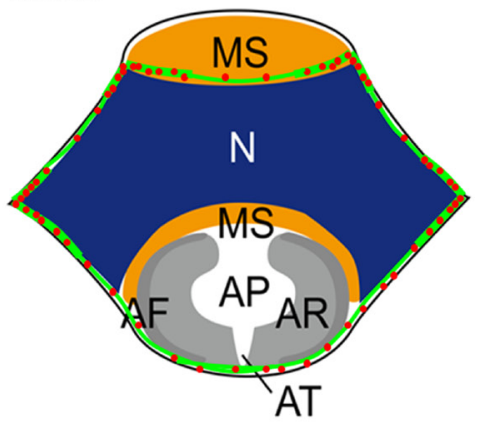

Figure 10: KIFC1 and microtubule expression pattern in late-stage spermatids. KIFC1 and microtubules surrounded the reshaping nucleus of the late spermatids (arrows). Red: KIFC1. green: microtubules. blue: DAPI labeled nucleus. N. nucleus, MS. membrane sheets, AV. acrosomal granule, AF. acrosomal filament, AR. acrosomal cap, AP. cloudy material in acrosomal cap, AT. acrosomal tubules. $($ bar $=10 \mu \mathrm{m})$.
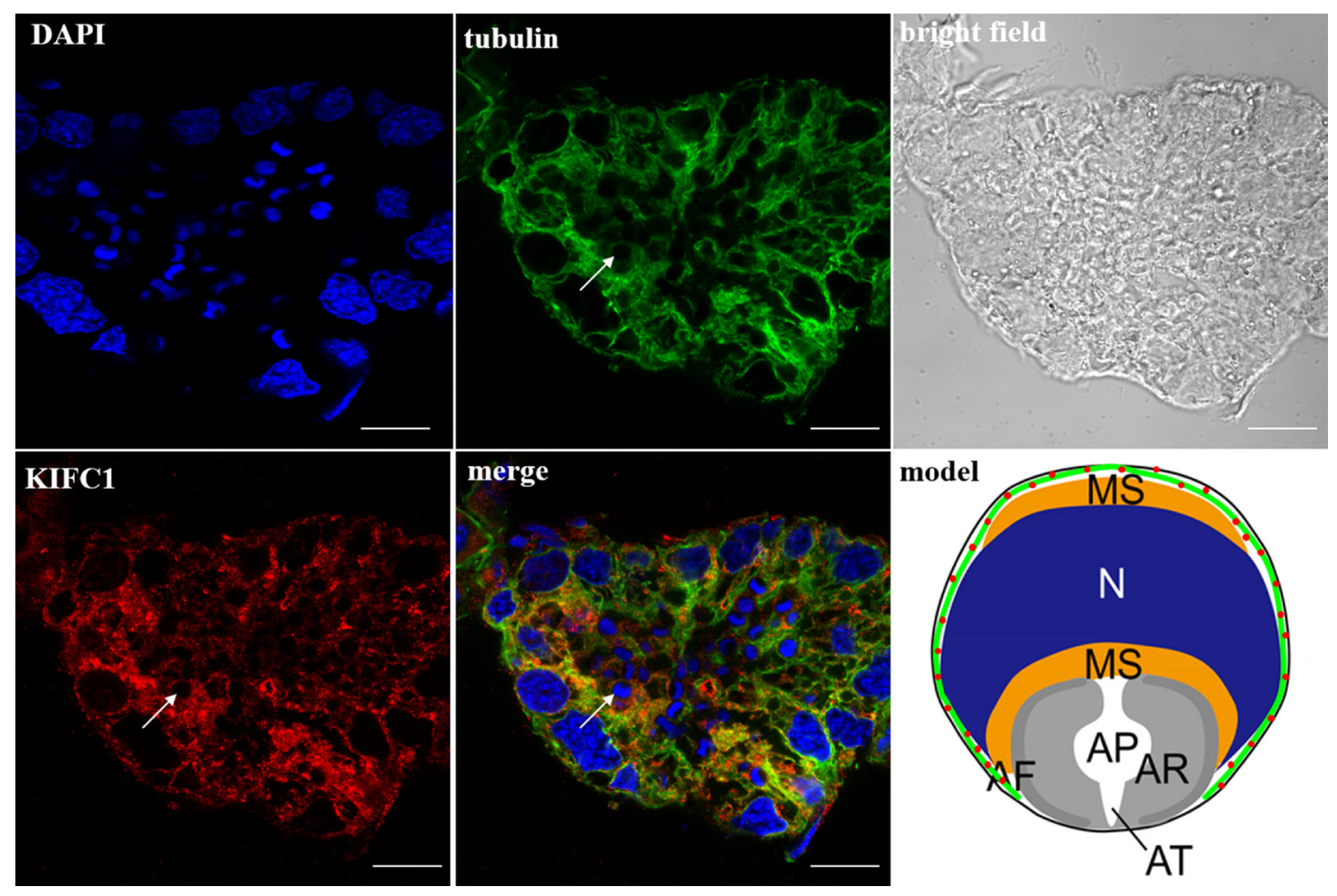

Figure 11: KIFC1 and microtubule expression pattern in mature sperm. KIFC1 and microtubules were located around the whole mature sperm (arrows). Red: KIFC1. green: microtubules. blue: DAPI labeled nucleus. N. nucleus, MS. membrane sheets, AV. acrosomal granule, AF. acrosomal filament, AR. acrosomal cap, AP. cloudy material in acrosomal cap, AT. acrosomal tubules. (bar $=10 \mu \mathrm{m})$. 
into functional acrosome. The kinesin superfamily motor proteins have been reported to move along microtubules carrying cargoes such as organelles, synaptic vesicles, protein complexes, mRNA, bare DNA, etc. [28, 29, 30]. KIFC1 as one member of the kinesin 14 family protein, was assumed to participate in the acrosome formation in spermiogenesis of $P$. clarkii.

\section{KIFC1 participates in $\boldsymbol{P}$. clarkii nuclear shaping}

The nuclear morphological changes are dominant in the evolution of sperm. In the mammals the sperm nuclear head was shaped by the microtubule-based manchette [31]. Kinesins like KIF27 and KIFC1-like motor were detected in the manchette, presumably promoting the nuclear

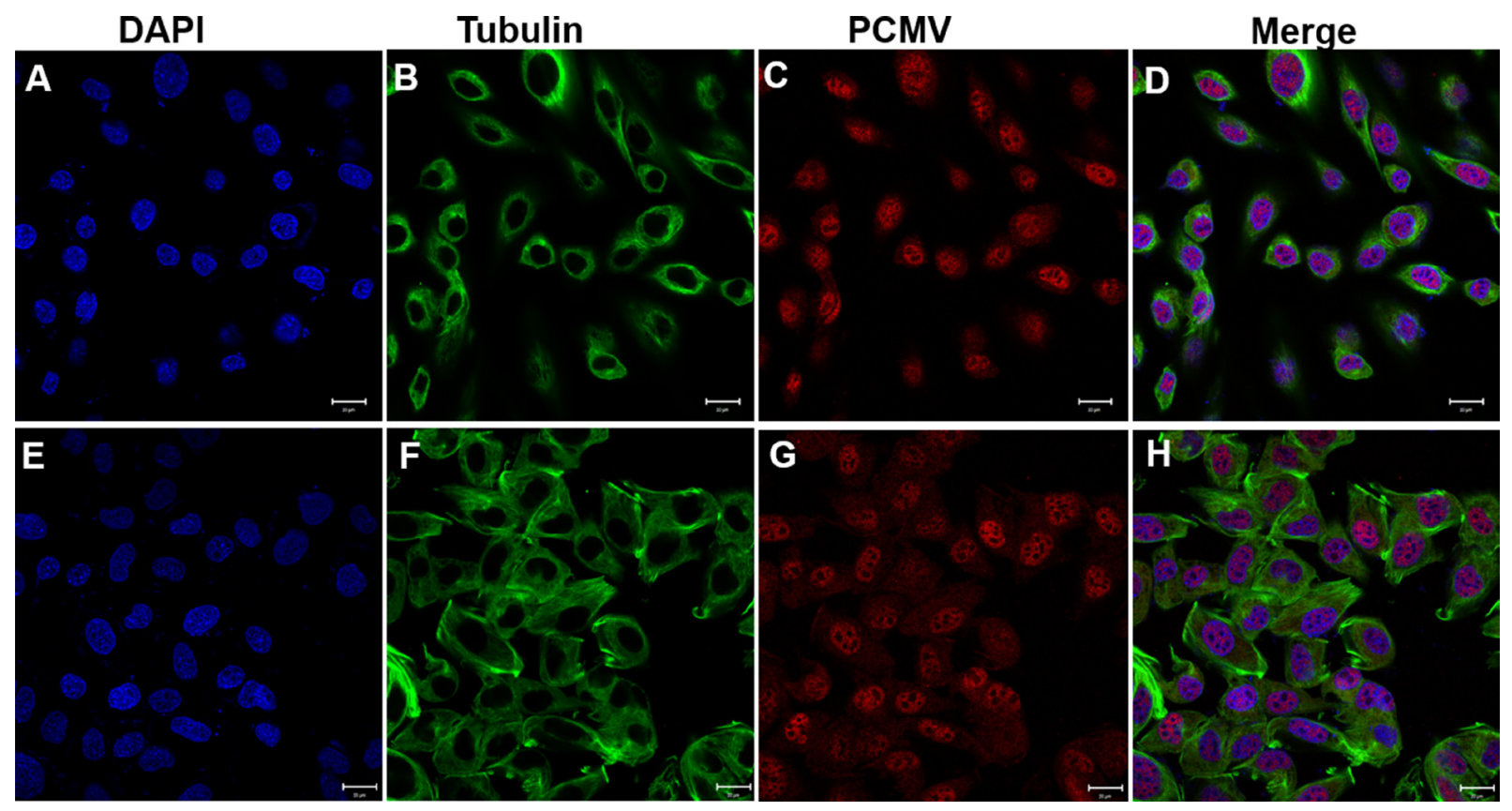

Figure 12: Effects of $\boldsymbol{P}$. clarkii kifcl overexpression on GC1 cell morphology. (A-D) control; (E-H) overexpression, A\&E. nucleus, B\&F. microtubule, C, pCMV, G, pCMV-KIFC1, D\&H. merge. 24 hours after transfection, the GC1 cells of control groups were circular or oval, the microtubules were dispersed around the nucleus (D). In the experimental groups, the microtubules were irregularly arranged (F), the cell and nucleus shape changed from circular and oval to fusiform (E, H). (bar $=20 \mu \mathrm{m})$.

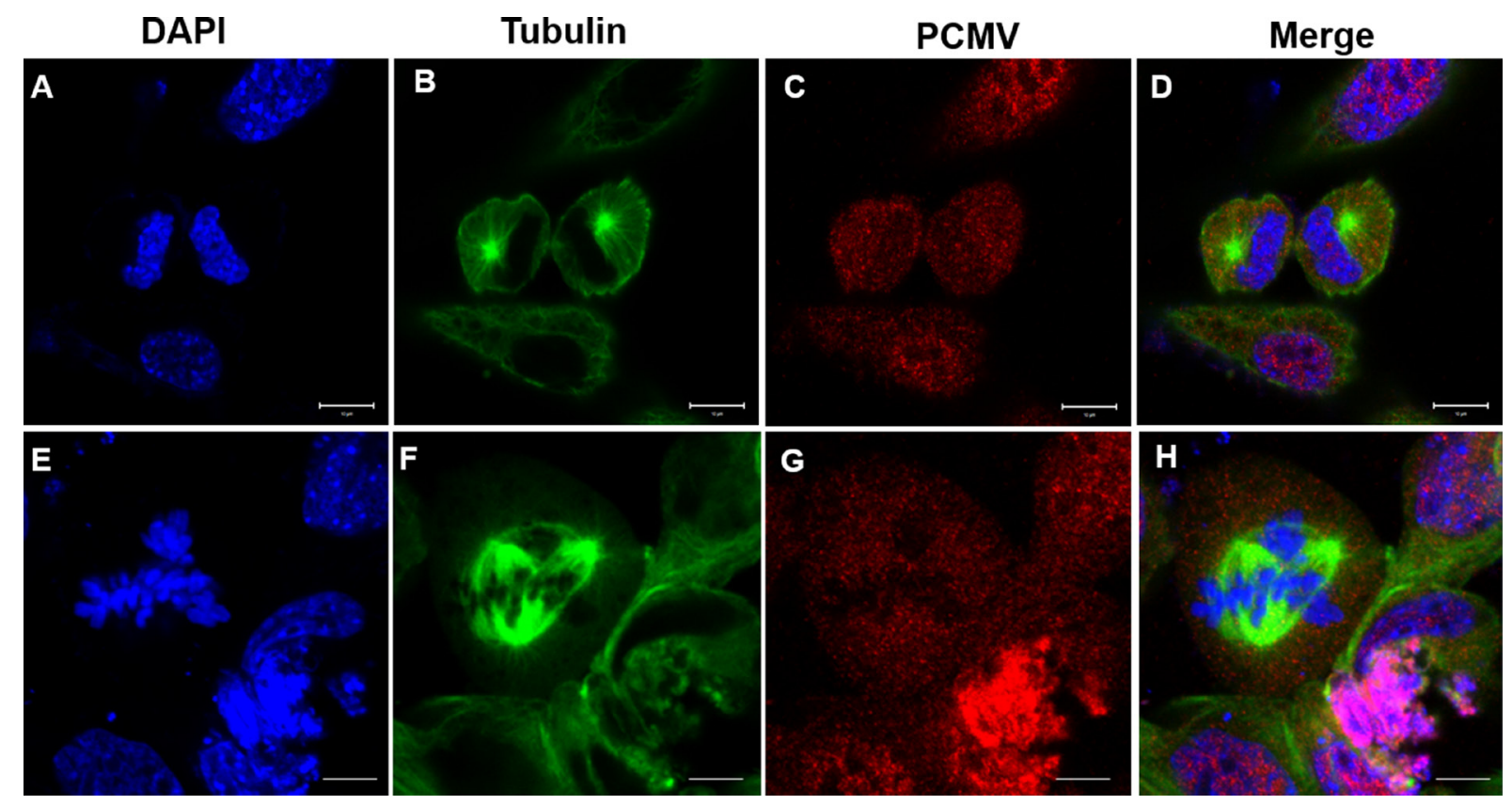

Figure 13: Effects of $\boldsymbol{P}$. clarkii kifc1 overexpression on GC1 cell mitosis. (A-D) control; (E-H) overexpression, A\&E. nucleus, B\&F. microtubule, C, pCMV, G, pCMV-KIFC1, D\&H. merge. The GC1 cells in control groups displayed normal mitosis with two spindle poles $(B, D)$. In the experimental groups there existed abnormal mitosis with three spindle poles $(\mathrm{F}, \mathrm{H})$. $(\mathrm{bar}=20 \mu \mathrm{m})$. 
shaping via the mechanical forces generated by walking on the manchette microtubules [7, 32]. Kinesins can not only move along microtubules, but also regulate the microtubule organization in different ways. For example, the kinesin-1 can change the microtubule orientation in the Drosophila axon via interplay with cortical dynein [33]. The kinesin-5 acts to restrain the number of minus end-distal microtubules that are transported into dendrites, suppression of kinesin-5 resulted in changes in dendritic morphology and microtubule organization [34]. During cell division, kinesin-12 (Kif15) and kinesin-5 (Eg5) cooperate to suppress microtubule depolymerization and drive the formation of parallel microtubule bundles that are essential for accurate chromosome segregation [35], kinesin-14 family proteins $\mathrm{HSET} / \mathrm{XCTK} 2$ control spindle length by cross-linking and sliding microtubules [36]. In our present study it was observed that KIFC1 and microtubules were located around the reshaping nucleus in the late-stage spermatids, probably changing the nuclear shape in the traditional "manchette-like" way. As primitive culture of $P$. clarkii spermatogenic cells has not been tried out yet, and mammal cell lines have been proved to be a convenient way to testify protein functions of lower species like crustaceans [37], we also attempted to overexpress the $P$. clarkii kifcl in mouse spermatogonia germ cell line (GC1) to clarify its functions in vitro. It was found to induce the changes in microtubule organization as well as the cellular and nuclear morphologies of GC1 cells (Figure 12). Therefore, it is reasonable to assume that KIFC1 contributed in $P$. clarkii sperm nuclear shaping in the traditional microtubule-dependent manner.

\section{Functional analysis of KIFC1 in P. clarkii spermiogenesis}

The full significance of this motor protein cannot be deduced from morphological observations alone. RNA interference (RNAi) is a biological process in which the
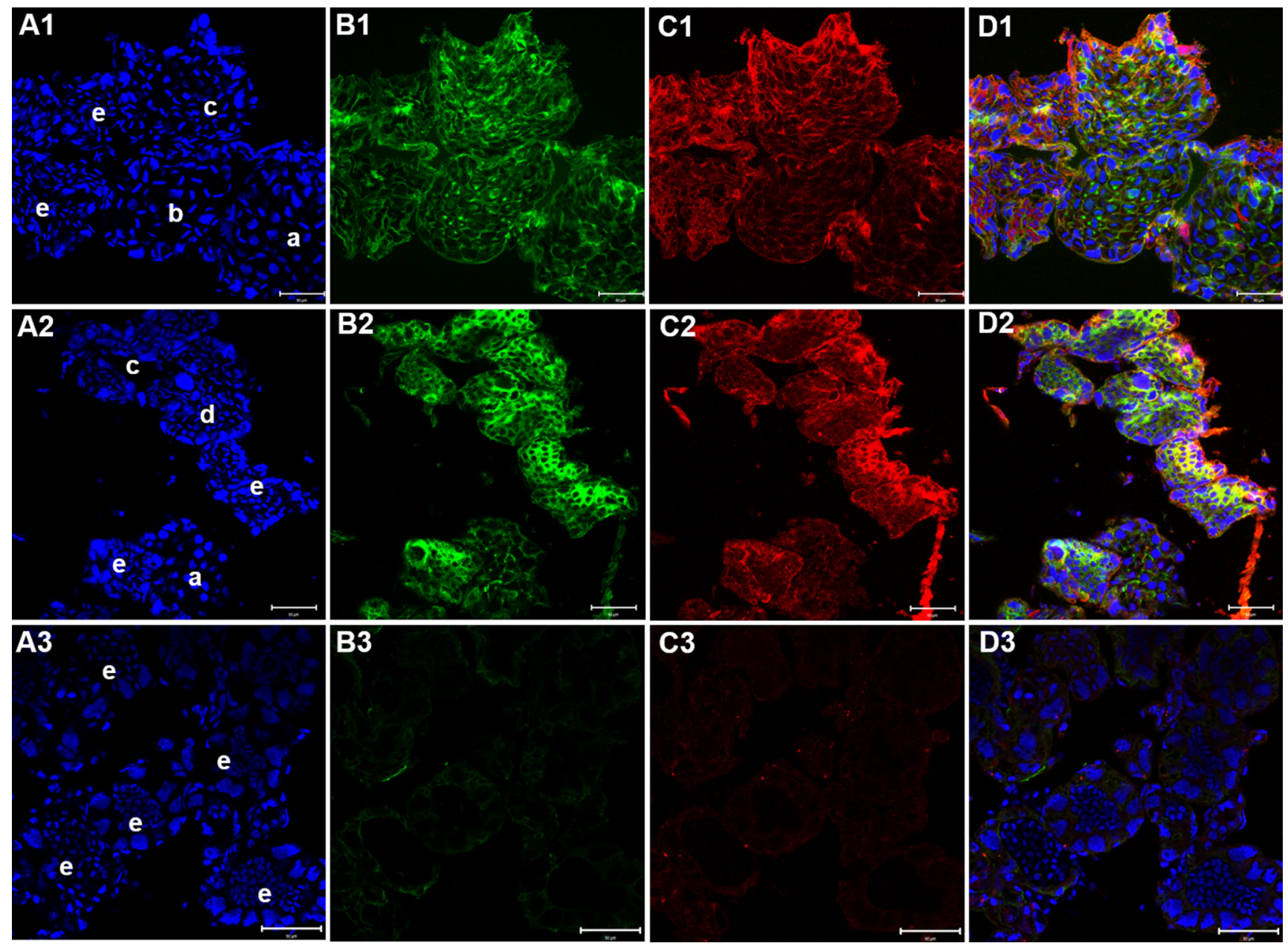

Figure 14: Effects of kifc1 RNAi on $\boldsymbol{P}$. clarkii testes. (A1-D1) blank control; (A2-D2) negative control; (A3-D3) experimental groups. The testes of blank groups showed high expression of KIFC1 (C1) and microtubules (B1). Spermatocytes (A1a), various stages of spermatids (A1 b\&c) and mature sperm (A1e) were observed in testes. The testes of negative control groups displayed similar pattern with the blank control (B1-B3). In the experimental groups, the expression levels of KIFC1 and microtubules were significantly reduced (C2, C3), spermatocytes and different stages of spermatids were not found, and only mature sperm were observed in the kifcl-siRNA groups (A3e). A1-C1, DAPI labeled nucleus; A2-C2, microtubules; A3-C3, KIFC1; A4-C4, merge. $($ bar $=50 \mu \mathrm{m})$. 
exogenous or endogenous short double-stranded RNA molecules (dsRNA) inhibit gene expression or translation by neutralizing targeted mRNA molecules [38]. RNAi has been widely used to inhibit virus infections in shrimps [39, 40] and to study gene functions [41]. Whilst dsRNAs were mostly used in shrimps, small interfering RNAs (siRNAs) have also been proved to be capable of proficient genespecific knockdown [42]. siRNAs combined into an nucleic acid complex, forming RNA induced silencing complex (RISC) which acted as a template to identify and destroy the mRNA of homologous sequence, resulting in specific inhibition of gene expression [43]. In the present study we designed and synthesized specific kifcl-siRNAs and screen out the effective ones to inhibit the KIFC1 expression in P. clarkii. It was found that the decreased levels of KIFC1 expression in testes were closely correlated with the abnormal testes in kifclsiRNA groups, in which the spermiogenesis was totally inhibited when the KIFC1 expression was reduced, with the disappear of spermatocytes and spermatids, the mature sperm were also significantly reduced 9 days post injection. This is consistent with its homologous proteins in other species. For example, the decreased expression of KIFC1 in human testes was correlated with Globozoospermic defects [44]. KIFC1 has been reported to be essential for bipolar spindle formation and genomic stability in the primary human fibroblast IMR-90 cell, KIFC1 knock-down with specific shRNA induced 17\% of cells with multiple microtubule organizing centers (MTOCs) in mitosis [45]. Overexpression of P. clarkii kifcl in GC1 cells also resulted in abnormal mitosis as reflected by appearance of three spindle poles (Figure 13). In one case, the loss of the kinesin-14 orthologues (KIN141, KIN142) in Tetrahymena led to severe defects in the chromosome segregation during both mitosis and meiosis [46], in another case the maize mutant divergent spindle-1 $(d v 1)$ caused failures in meiotic spindle assembly and a decrease in pollen viability [47]. This may partly explain the abnormal spermiogenesis observed in kifcl-siRNA group.

In summary, the present study used the crayfish P. clarkii as a model to discuss the importance of kinesin-14 motor protein KIFC1 in the spermiogenesis of crustacean. It has been proved to participate in the sperm maturation in multiple ways, including acrosome formation and nuclear shaping, which are the prerequisites for sperm to fertilize an egg. Loss of KIFC1 resulted in total inhibition of spermiogenesis. It is speculated that the abnormal early spermatids underwent apoptosis as a result of unsuccessful meiosis, or that the developing spermatids underwent apoptosis as a result of incomplete structure in KIFC1-loss testes. We also attempt to overexpress the full length of $P$. clarkii kifcl in cultured cells to clarify its functions in vitro, and we hope this method could help crustacean specialists to explore gene functions in future studies.

\section{MATERIALS AND METHODS}

\section{Animal preparation}

The lobster ( $P$. clarkii) was purchased from Luojia Village market (Hangzhou, China). The adult and active ones were selected for our experiment. We collect tissues to extract RNA and proteins including testes, hearts, muscles, and green glands from the males and ovaries from the females. For RNAi experiments, the adult and mature male red lobster with a consistent weight of $18 \pm 2 \mathrm{~g}$ were used. When bought from the market, the lobster were acclimatized in the laboratory for more than 1 week $\left(20^{\circ} \mathrm{C}\right.$, light/dark: $\left.12 \mathrm{~h} / 12 \mathrm{~h}\right)$ before experiments.

No specific permits were required for the collection of samples.

\section{Hematoxylin-eosin (HE) staining}

The testes from adult male lobster were fixed in $4 \%$ paraformaldehyde for overnight and then dehydrated in a series of gradient alcohol as $70 \%, 80 \%, 95 \%$ for $15 \mathrm{~min}$ each and $100 \%$ twice for 15 mins. After that the samples were transferred into alcohol \& xylene mixture for 15 min, and then in xylene for $10 \mathrm{~min}$ followed by $30 \mathrm{~min}$ in 50\% xylene \& 50\% paraffin mixture. The samples were soaked in melting paraffin for $3 \mathrm{~h}$ before embedded in paraffin. When solidified the paraffin embedding fasts were cut into $6 \mu \mathrm{m}$ sections. After rehydrated in gradient alcohol as $100 \%, 95 \%, 80 \%, 70 \%$ and water for $5 \mathrm{~min}$ each, the slides were stained with hematoxylin for $2 \mathrm{~min}$ and eosin-Y for $1 \mathrm{~min}$. The slides were then dehydrated in gradient alcohol and permuted by xylene and sealed with neutral balsam. The pictures were taken by microscope (Olympus BX 40).

\section{RNA extraction and reverse transcript PCR}

We used Phase Lock Gel ${ }^{\mathrm{TM}}$ Heavy with Trizol A ${ }^{+}$ Reagent (Tiangen Biotech, Beijing, China) to extract total RNA. We collect the tissue of hearts, muscles, green glands, gills, and testis from lobster, treated with grinder in Trizol, then transferred to Phase Lock Gel ${ }^{\mathrm{TM}}$ Heavy. With the treatment of chloroform, isopropanol and $75 \%$ ethanol, we centrifuge to get the RNA. The whole procedure is RNase-free.

For normal reverse transcription, we chose the PrimeScript ${ }^{\mathrm{HRT}}$ Reagent Kit (Takara, Dalian, China). The $3^{\prime}$ and 5' reverse transcription was processed following the protocol of Smart RACE cDNA Amplification Kit (CloneTech, Mountain View, USA).

\section{Full-length cDNA cloning}

The primer used in this experiment was designed by Cong-cong Hou in the conservative region of kifcl of 
M. rosenbergii with the software Primer Premier 5. PCR programs were set as follows: $94^{\circ} \mathrm{C}$ for $4 \mathrm{~min} ; 32$ cycles of $94^{\circ} \mathrm{C}$ for $30 \mathrm{~s}, 60^{\circ} \mathrm{C}$ for $30 \mathrm{~s}$, and $72^{\circ} \mathrm{C}$ for $30 \mathrm{~s}$; and $72^{\circ} \mathrm{C}$ for $10 \mathrm{~min}$ for the final extension. The sample was separated by agarose electrophoresis. The purified DNA was ligated to PMD-18T and transformed to the competent cells, which were sent to Biosune Company (Shanghai, China) for sequencing.

Then with the sequence of the middle fragment, we designed nested primers for Rapid Amplification of cDNA Ends (RACE). Here are the PCR programs for the outer $3^{\prime} \mathrm{RACE}$ : $94^{\circ} \mathrm{C}$ for $4 \mathrm{~min}$; 6 cycles of $94^{\circ} \mathrm{C}$ for 30 $\mathrm{s}, 65^{\circ} \mathrm{C}$ (Touch- down $-0.5^{\circ} \mathrm{C}$ ) for $30 \mathrm{~s}$, and $72^{\circ} \mathrm{C}$ for $40 \mathrm{~s}$; then 29 cycles of $94^{\circ} \mathrm{C}$ for $30 \mathrm{~s}, 62^{\circ} \mathrm{C}$ for $30 \mathrm{~s}$, and $72^{\circ} \mathrm{C}$ for $40 \mathrm{~s} ; 72^{\circ} \mathrm{C}$ for $10 \mathrm{~min}$ for the final extension. Then the production was put to inner extension by the same program except the extension temperature adjusted from $62^{\circ} \mathrm{C}$ to $61^{\circ} \mathrm{C}$ and one more cycle.

The programs of $5^{\prime}$ are as follow: $94^{\circ} \mathrm{C}$ for $4 \mathrm{~min} ; 6$ cycles of $94^{\circ} \mathrm{C}$ for $30 \mathrm{~s}, 70^{\circ} \mathrm{C}$ (Touch- down $-0.5^{\circ} \mathrm{C}$ ) for $30 \mathrm{~s}$, and $72^{\circ} \mathrm{C}$ for $1 \mathrm{~min}$; then 31 cycles of $94^{\circ} \mathrm{C}$ for 30 $\mathrm{s}, 64^{\circ} \mathrm{C}$ for $30 \mathrm{~s}$, and $72^{\circ} \mathrm{C}$ for $1 \mathrm{~min} ; 72^{\circ} \mathrm{C}$ for $10 \mathrm{~min}$ for the final extension.

Primers used are listed in the Table 1.

\section{Putative protein sequence analysis and phylogenetic analysis}

The putative KIFC1 protein sequence alignment and the phylogenetic tree were made by Mega 6. The phylogenetic tree were built by the Mega 6 using Neighbor-joining method and examined by bootstrap test with the replication of 1000 . The protein 3-D structures were predicted by I-TASSER (http:// zhanglab.ccmb.med.umich.edu/I-TASSER/) and the functional units in the proteins were analyzed in The Conserved Domain Database (http://www.ncbi.nlm. nih.gov/cdd), the similarities with their homologues were analyzed by using NCBI-blastp (https://blast.ncbi. nlm.nih.gov/Blast.cgi?PROGRAM=blastp\&PAGE_ TYPE=BlastSearch\&LINK_LOC=blasthome).

\section{Semi-quantitative RT-PCR analysis of $k i f c 1$ mRNA}

We conducted Semi-quantitative RT-PCR to distinguish the kifcl mRNA expression of different tissues of lobsters. We used the reversed cDNA of heart, muscle, green gland, gill, and testis for the Semi-quantitative RTPCR. We designed different pairs of primers of kifcl and control, $\beta$-actin. PCR programs were set as follows: $94^{\circ} \mathrm{C}$ for $4 \mathrm{~min} ; 35$ cycles of $94^{\circ} \mathrm{C}$ for $30 \mathrm{~s}, 60^{\circ} \mathrm{C}$ for $30 \mathrm{~s}$, and $72^{\circ} \mathrm{C}$ for $30 \mathrm{~s} ; 72^{\circ} \mathrm{C}$ for $10 \mathrm{~min}$ for the final extension. The products were examined by electrophoresis on $1 \%$ agarose gel. The bands were revealed by DNA gel green and analyzed by software Image J.

\section{Western blot}

Four tissues including heart, muscle, green gland and testis were homogenized in RIPA Lysis Buffer (Beyotime Biotech, China) and the protease inhibitor PMSF (Beyotime Biotech, China). The samples were centrifuged in $13,000 \mathrm{rpm}$ for $15 \mathrm{~min}$ at $4^{\circ} \mathrm{C}$ and the supernatants were collected. The total protein concentrations were measured and diluted to $1 \mu \mathrm{g} / \mu \mathrm{L}$ and conducted Western blot in 12\% SDS-PAGE gels, each sample with a total protein amount of $10 \mu \mathrm{g}$. Transferred to PVDF membrane (Bio-Rad, California, USA), proteins were blocked in 5\% non-fat milk for 2 hours. Then the membrane was incubated overnight in KIFC1 antibody (diluted 1:400 in PBS-milk) in $4^{\circ} \mathrm{C}$ and washed with PBST 3 times, 10 minutes each time. The rabbit KIFC1 polyclonal antibody used in this experiment was firstly designed for the KIFC1 of Exopalaemon modestus and described in the former study of our laboratory [3]. Membrane was then incubated in secondary antibody (HRP conjugated goat anti-rabbit IgG diluted in 1:1000 PBS-milk) for 1 hour. After washing 5 times (10 minutes each time), the image of the membrane was detected with enhanced chemiluminescent agents from SuperSignal West PicoTrial Kit (Thermo, Massachusetts, USA) by the chemiluminescence imaging. $\beta$-actin was used as control, the poly-anti- $\beta$-actin was bought from Sangon Biotech, China and used with 1: 1000 dilution in present study.

\section{in situ hybridization (ISH)}

The ISH was conducted as described by Helmprobst et al. (2017) [48]. The testes were collected and fixed in $4 \%$ paraformaldehyde (PFA in $\mathrm{PBS}, \mathrm{pH} 7.4$ ) in the $4^{\circ} \mathrm{C}$ for 2 hours. After rinsing in $\mathrm{PBS}$, the samples were dehydrated in $0.5 \mathrm{M}$ sucrose ( dissolved in PBS ) in $4^{\circ} \mathrm{C}$ for another 2 hours, then embedded by Tissue-Tek O.C.T. Compound to store in the $-40^{\circ} \mathrm{C}$. For ISH, the samples were cut into $10 \mu \mathrm{m}$ sections with Cryostat microtome. A length of 502 bp kifcl fragment was cloned from cDNA and ligated to PGEM-T Vector with Sp6 and T7 transcription sites. Sense and antisense probe was transcribed with Sp6 and T7 RNA transcription enzymes (Promega, Madison, Wisconsin, USA) and the NTP DIG RNA labeling Mix (Roche, Basel, Switzerland), according to the Manufacturer's protocols. After hybridization with the DIG-RNA antisense probes, the slides were incubated with Anti-Digoxigenin-AP Fab fragments (Roche, Basel, Switzerland) for overnight, then stained with NBT/BCIP mix (Promega, Madison, Wisconsin, USA). The slides were then dehydrated in gradient alcohol as 50\%, 70\%, 90\%, and $100 \%$ for $15 \mathrm{~min}$ each and permuted by xylene before sealed with neutral balsam. The sense probes were used as negative control. The pictures were taken by microscope (Olympus BX40). The bands were analyzed by software Image J. 
Table 1: Primers used in kifcl cloning and semi-quantitative RT-PCR

\begin{tabular}{lll}
\hline Primer & Sequence & Function \\
\hline F & CCCTTTTAAATCCCAAGCTGCTC & Intermediate segment \\
R & TTTGCTTACGGACAGACAGG & Intermediate segment \\
3' F1 & TGAAAGGACGTGGAAATGGC & 3' RACE \\
3'F2 & TCTGAAGGATAAAGGCTGGATT & 3' RACE \\
5'R & TAAGTGTGGCAGACAACTCATCCCGC & 5' RACE \\
RT-actin-F & CCCAACAATGCTGACTGAA & Internal control of Semi-quantitative RT-PCR \\
RT-actin-R & CGGTGGTGGTGAAGGAATA & Internal control of Semi-quantitative RT-PCR \\
RT-kifc1-F & CCTGAAAGGACGTGGAAATG & Semi-quantitative RT-PCR \\
RT-kifc1-R & AAACGGAAGACGGAATGTGA & Semi-quantitative RT-PCR \\
\hline
\end{tabular}

\section{Immunofluorescent assay (IF)}

The testes were collected and fixed in 4\% PFA in the $4^{\circ} \mathrm{C}$ overnight. After rinsing in PBS, the samples were dehydrated in $0.5 \mathrm{M}$ sucrose in $4^{\circ} \mathrm{C}$ overnight then embedded by Tissue-Tek O.C.T. Compound to store in the $-40^{\circ} \mathrm{C}$. For IF, the samples were cut into $10 \mu \mathrm{m}$ sections with Cryostat microtome. The sections were rehydrated with PBST (Triton) for 15 minutes, and then blocked with 5\% BSA (PBST) for 1 hour in room temperature. Experiment groups were incubated with primary antibodies (anti-KIFC11:80 in BSA) and covered by parafilm at $4{ }^{\circ} \mathrm{C}$ overnight. Slides of control group were incubated with BSA without adding primary antibody. After this, they were washed 3 times in $0.1 \%$ PBST for 15 $\mathrm{min}$ each. The tissue sections were then incubated at room temperature with the secondary antibodies (555 donkeyanti-rat IgG, 1:500, Alexa Fluor ) and rat monoclonal anti-tubulin antibody (1:100 in BSA) (sigma, St. Louis, Mo., USA) for 1 hour. After that, the sections were washed 3 times in $0.1 \%$ PBST for $10 \mathrm{~min}$ each. Before mounting, the sections were added dropwise with DAPI (Beyotime, Dalian, China) to stain the DNA. Then with Antifade Mounting Medium (Beyotime Biotech, China), the sections were mounted and quickly observed with a Confocal Laser-scanning Microscope (CLSM 510) (Carl Zeiss, Germany).

\section{Overexpression of P. clarkii KIFC1 in GC1 cells}

The $P$. clarkii kifcl expression construct was generated by inserting the full length $P$. clarkii-kifcl cDNA into pCMV-N-Flag (Beyotime Biotechnology, Shanghai, China) with BamHI/SpeI restriction sites, and verified by sequencing (Biosune Company, Shanghai, China). We then use EZNA Plasmid Miniprep 172 Kit II (Omega Bio-Tek, USA) to prepare the endotoxin-free plasmids, according to manufacturer's instructions. The mouse spermatogonia cell line GC1 was purchased from ATCC, and cultured in Dulbecco's Modified Eagle's Medium (DMEM) with penicillin $(100 \mathrm{U} / \mathrm{ml})$ and streptomycin $(100 \mu \mathrm{g} / \mathrm{ml})$ as well as $10 \%$ heat inactivated fetal bovine serum (FBS).
The cultures were incubated at $37{ }^{\circ} \mathrm{C}$ with a humidified atmosphere of $5 \% \mathrm{CO} 2$. The PCMV-N-Flag- $P$. clarkiikifcl recombinant plasmids were then transfected into the 24-well plate GC1 cell cultures (with round cover glass slide inside each well) using Invitrogen ${ }^{\mathrm{TM}}$ Lipofectamine ${ }^{\circledR}$ $1753000 \mathrm{Kit}$, the pCMV-N-FLAG plasmids were used as a control. The overexpression was determined by IF staining 24 hours after transfection.

For IF, the cells were fixed with 4\% PFA for $15 \mathrm{~min}$ and then wash with $\mathrm{PBS}$, followed by permeabilization with $0.25 \%$ TritonX-100/PBS for 10 min. Block the slides with $1 \% \mathrm{BSA} / \mathrm{PBST}$ for $30 \mathrm{~min}$, and then cells were incubated with rabbit monoclonal Flag antibody (1:100) overnight at $4^{\circ} \mathrm{C}$. After this, the slides were washed with PBST (TritonX-100) and incubated with secondary antibodies for 1 hour at room temperature (Alexa Fluor 555-labeled Donkey Anti-Rabbit IgG (H+L), 1:500; Monoclonal Anti-alpha-Tubulin-FITC antibody, 1:100). After wash away the secondary, slides were incubated with DAPI (Beyotime, Shanghai, China) for $5 \mathrm{~min}$. Then slides were added dropwise by Antifade Mounting Medium (Beyotime, Shanghai, China) and sealed with nail polish. Observe and capture the pictures under the Confocal Laser-scanning Microscope (CLSM510; Carl Zeiss Germany).

\section{siRNA silencing}

Three different sets of oligos were designed by Thermo Fisher BLOCK-iTTM RNAi Designer (http:// rnaidesigner.thermofisher.com/rnaiexpress/) for knocking down of endogenous KIFC1, and one set of oligos were designed for GFP as negative control (Table 2). The siRNAs were synthesized using TaKaRa in vitro Transcription T7 Kit. Before injecting into lobster, the siRNA knockdown experiments were conducted in vitro via co-transfection of three different siRNAs with the PCMV-N-Flag-P. clarkii-kifcl recombinant plasmids into GC1 cells, $1 \mu \mathrm{g}$ recombinant plasmid was co-added with $0.6 \mu \mathrm{g}$ siRNA except the control groups. The knockdown efficiency was examined 48 hours after transfection by Western blot using PCMV antibody (1:1000). 
Table 2: Sequences in siRNA synthesis

\begin{tabular}{ll}
\hline Name & Sequence \\
\hline 1-Oligo1 & GATCACTAATACGACTCACTATAGGGCAGTCCTCTGTAGGTACCAAGAGCTTT \\
1-Oligo2 & AAAGCTCTTGGTACCTACAGAGGACTGCCCTATAGTGAGTCGTATTAGTGATC \\
1-Oligo3 & AACAGTCCTCTGTAGGTACCAAGAGCTCCCTATAGTGAGTCGTATTAGTGATC \\
1-Oligo4 & GATCACTAATACGACTCACTATAGGGAGCTCTTGGTACCTACAGAGGACTGTT \\
2-Oligo1 & GATCACTAATACGACTCACTATAGGGTGGAACTTGAGAAACAGGATCTTAATT \\
2-Oligo2 & AATTAAGATCCTGTTTCTCAAGTTCCACCCTATAGTGAGTCGTATTAGTGATC \\
2-Oligo3 & AATGGAACTTGAGAAACAGGATCTTAACCCTATAGTGAGTCGTATTAGTGAT \\
2-Oligo4 & GATCACTAATACGACTCACTATAGGGTTAAGATCCTGTTTCTCAAGTTCCATT \\
3-Oligo1 & GATCACTAATACGACTCACTATAGGGCAAGAAGAAGTTGACCGACTCAAAT TT \\
3-Oligo2 & AAATTTGAGTCGGTCAACTTCTTCTTGCCCTATAGTGAGTCGTATTAGTGATC \\
3-Oligo3 & AACAAGAAGAAGTTGACCGACTCAAATCCCTATAGTGAGTCGTATTAGTGATC \\
3-Oligo4 & GATCACTAATACGACTCACTATAGGGATTTGAGTCGGTCAACTTCTTCTTGTT \\
GFP-1 & GATCACTAATACGACTCACTATAGGGTCCTTCGCAAGACCCTTCCTCTATATT \\
GFP-2 & AATATAGAGGAAGGGTCTTGCGAAGGACCCTATAGTGAGTCGTATTAGTGATC \\
GFP-3 & AATCCTTCGCAAGACCCTTCCTCTATACCCTATAGTGAGTCGTATTAGTGATC \\
GFP-4 & GATCACTAATACGACTCACTATAGGGTATAGAGGAAGGGTCTTGCGAAGGATT
\end{tabular}

The lobster were divided into three groups, each contained 20 individuals. The effective kifcl-siRNAs were then injected into the body cavity, each lobster was injected with $20 \mu \mathrm{g} k i f c 1$-siRNA (dissolved in PBS), the blank control groups were injected with PBS, and the negative control group were injected with same amount of $g f p$-siRNA. After 3 and 9 days the lobster were sacrificed and the testes were collected and fixed in 4\% PFA in the $4^{\circ} \mathrm{C}$ refrigerator overnight. The samples were then incubated in $0.5 \mathrm{M}$ sucrose in $4^{\circ} \mathrm{C}$ overnight, and then embedded by Tissue-Tek O.C.T. The efficiency of siRNA knockdown in vivo and the effects on testes were detected using IF staining. The experiments were conducted more than three times.

\section{Abbreviations}

ISH: in situ hybridization; AFS: acroframosome; UTR: untranslated region; ORF: open reading frame; TEM: transmission election microscope; GC1: mouse spermatogonia germ cell line; RNAi: RNA interference; dsRNA: double-stranded RNA molecules; siRNAs: small interfering RNAs; MTOCs: multiple microtubule organizing centers; HE: Hematoxylineosin; RACE: Rapid Amplification of cDNA Ends; ISH: in situ hybridization; IF: Immunofluorescent; DMEM: Dulbecco's Modified Eagle's Medium; FBS: fetal bovine serum; PVDF: poly vinylidene flouride; RIPA: radio immunprecipitation assay; PMSF: phenylmethanesulfonyl fluoride; PBS: phosphate buffer saline; HRP: horseradish peroxidase; PFA: paraformaldehyde; GFP: green fluorescent protein.

\section{Authors' contributions}

D.D.M., L.B. and W.X.Y designed the experiments. D.D.M. and L.B. performed all the experiments and cooperated with W.X.Y. to analyze the data. D.D.M. wrote the manuscript and W.X.Y. revised the manuscript. All authors reviewed the manuscript.

\section{ACKNOWLEDGMENTS}

The authors are grateful to all members of the Sperm Laboratory in Zhejiang University for their valuable assistance on the present work.

\section{CONFLICTS OF INTEREST}

None.

\section{FUNDING}

This project was supported by the Natural Science Foundation of China (Nos. 31572603 and 41276151).

\section{REFERENCES}

1. Hirokawa N, Noda Y. Intracellular transport and kinesin superfamily proteins, KIFs: structure, function, and dynamics. Physiol Rev. 2008; 88:1089-118.

2. Hirokawa N, Noda Y, Tanaka Y, Niwa S. Kinesin superfamily motor proteins and intracellular transport. Nat Rev Mol Cell Biol. 2009; 10:682-96. 
3. Hou CC, Yang WX. Acroframosome-dependent KIFC1 facilitates acrosome formation during spermatogenesis in the caridean shrimp Exopalaemon modestus. PLoS One. 2013; 8:e76065.

4. Li Z, Pan CY, Zheng BH, Xiang L, Yang WX. Z BH, Xiang L, Yang WX. Immunocytochemical studies on the acroframosome during spermiogenesis of the caridean shrimp Macrobrachium nipponense (Crustacea, Natantia). Invertebr Reprod Dev. 2010; 54:121-31.

5. Yu K, Hou L, Zhu JQ, Ying XP, Yang WX. KIFC1 participates in acrosomal biogenesis, with discussion of its importance for the perforatorium in the Chinese mitten crab Eriocheir sinensis. Cell Tissue Res. 2009; 337:113-23.

6. Wang W, Zhu JQ, Yu HM, Tan FQ, Yang WX. KIFC1-like motor protein associates with the cephalopod manchette and participates in sperm nuclear morphogenesis in Octopus tankahkeei. PLoS One. 2010; 5:e15616.

7. Tan FQ, Ma XX, Zhu JQ, Yang WX. The expression pattern of the C-terminal kinesin gene kifc1 during the spermatogenesis of Sepiella maindroni. Gene. 2013; 532:53-62.

8. Hu JR, Liu M, Wang DH, Hu YJ, Tan FQ, Yang WX. Molecular characterization and expression analysis of a KIFC1-like kinesin gene in the testis of Eumeces chinensis. Mol Biol Rep. 2013; 40:6645-55.

9. Ibáñez I, Diez JM, Miller LP, Olden JD, Sorte CJ, Blumenthal DM, Bradley BA, D'Antonio CM, Dukes JS, Early RI, Grosholz ED, Lawler JJ. Integrated assessment of biological invasions. Ecol Appl. 2014; 24:25-37.

10. Nunes AL, Orizaola G, Laurila A, Rebelo R. Rapid evolution of constitutive and inducible defenses against an invasive predator. Ecology. 2014; 95:1520-30.

11. Hess RA, Renato de Franca L. Spermatogenesis and cycle of the seminiferous epithelium. Adv Exp Med Biol. 2008; 636:1-15.

12. Peng Q, Nunes LM, Greenfield BK, Dang F, Zhong H. Are Chinese consumers at risk due to exposure to metals in crayfish? A bioaccessibility-adjusted probabilistic risk assessment. Environ Int. 2016; 88:261-68.

13. Barbee GC, McClain WR, Lanka SK, Stout MJ. Acute toxicity of chlorantraniliprole to non-target crayfish (Procambarus clarkii) associated with rice-crayfish cropping systems. Pest Manag Sci. 2010; 66:996-1001.

14. Sarojini R, Nagabhushanam R, Fingerman M. Naphthaleneinduced atresia in the ovary of the crayfish, Procambarus clarkii. Ecotoxicol Environ Saf. 1995; 31:76-83.

15. Fanjul-Moles ML, Escamilla-Chimal EG, Gloria-Soria A, Hernández-Herrera G. The crayfish Procambarus clarkii CRY shows daily and circadian variation. J Exp Biol. 2004; 207:1453-60.

16. Aquiloni L, Gherardi F. The use of sex pheromones for the control of invasive population of the crayfish Procambarus clarkii: A field study. Hydrobiologia. 2010; 649:249-54.
17. Kozak P, Gallardo JM, Garcia JC. Light preferences of red swamp crayfish (Procambarus clarkii). Hydrobiologia. 2009; 636:499-503.

18. Dong WL, Hou CC, Yang WX. Mitochondrial prohibitin and its ubiquitination during crayfish Procambarus clarkii spermiogenesis. Cell Tissue Res. 2015; 359:679-92.

19. Pannu V, Rida PC, Ogden A, Turaga RC, Donthamsetty S, Bowen NJ, Rudd K, Gupta MV, Reid MD, Cantuaria G, Walczak CE, Aneja R. HSET overexpression fuels tumor progression via centrosome clustering-independent mechanisms in breast cancer patients. Oncotarget. 2015; 6:6076-91. doi: 10.18632/oncotarget.3475

20. Walczak CE, Verma S, Mitchison TJ. XCTK2: a kinesinrelated protein that promotes mitotic spindle assembly in Xenopus laevis egg extracts. J Cell Biol. 1997; 136:859-70.

21. Zhang P, Dai W, Hahn J, Gilbert SP. Drosophila Ncd reveals an evolutionarily conserved powerstroke mechanism for homodimeric and heterodimeric kinesin-14s. Proc Natl Acad Sci USA. 2015; 112:6359-64.

22. Mieck C, Molodtsov MI, Drzewicka K, van der Vaart B, Litos G, Schmauss G, Vaziri A, Westermann S. Noncatalytic motor domains enable processive movement and functional diversification of the kinesin-14 Kar3. eLife. 2015; 4:e04489.

23. Welburn JP. The molecular basis for kinesin functional specificity during mitosis. Cytoskeleton (Hoboken). 2013; 70:476-93.

24. Sati L, Seval-Celik Y, Unek G, Korgun ET, Demir R. The presence of kinesin superfamily motor proteins KIFC1 and KIF17 in normal and pathological human placenta. Placenta. 2009; 30:848-54.

25. Moses MJ. Spermiogenesis in the crayfish (Procambarus clarkii). I. Structural characterization of the mature sperm. J Biophys Biochem Cytol. 1961; 9:222-28.

26. Blasius TL, Reed N, Slepchenko BM, Verhey KJ. Recycling of kinesin-1 motors by diffusion after transport. PLoS One. 2013; 8:e76081.

27. Andreasson JO, Shastry S, Hancock WO, Block SM. The mechanochemical cycle of mammalian kinesin-2 KIF3A/B under load. Curr Biol. 2015; 25:1166-75.

28. Hirokawa N. Kinesin and dynein superfamily proteins and the mechanism of organelle transport. Science. 1998; 279:519-26.

29. Hirokawa N, Takemura R. Kinesin superfamily proteins and their various functions and dynamics. Exp Cell Res. 2004; 301:50-59.

30. Farina F, Pierobon P, Delevoye C, Monnet J, Dingli F, Loew D, Quanz M, Dutreix M, Cappello G. Kinesin KIFC1 actively transports bare double-stranded DNA. Nucleic Acids Res. 2013; 41:4926-37.

31. O'Donnell L. Mechanisms of spermiogenesis and spermiation and how they are disturbed. Spermatogenesis. 2015; 4:e979623.

32. Nozawa YI, Yao E, Gacayan R, Xu SM, Chuang PT. Mammalian Fused is essential for sperm head shaping and 
periaxonemal structure formation during spermatogenesis. Dev Biol. 2014; 388:170-80.

33. del Castillo U, Winding M, Lu W, Gelfand VI. Interplay between kinesin-1 and cortical dynein during axonal outgrowth and microtubule organization in Drosophila neurons. eLife. 2015; 4:e10140.

34. Kahn OI, Sharma V, González-Billault C, Baas PW. Effects of kinesin-5 inhibition on dendritic architecture and microtubule organization. Mol Biol Cell. 2015; 26:66-77.

35. Drechsler H, McAinsh AD. Kinesin-12 motors cooperate to suppress microtubule catastrophes and drive the formation of parallel microtubule bundles. Proc Natl Acad Sci USA. 2016; 113:E1635-44.

36. Cai S, Weaver LN, Ems-McClung SC, Walczak CE. Kinesin-14 family proteins HSET/XCTK2 control spindle length by cross-linking and sliding microtubules. Mol Biol Cell. 2009; 20:1348-59.

37. She ZY, Yang WX. Nucleocytoplasmic shuttling of SOX14A and SOX14B transcription factors. Oncotarget. 2017. doi: 10.18632/oncotarget.15134. [Epub ahead of print].

38. Mohr SE, Perrimon N. RNAi screening: new approaches, understandings, and organisms. Wiley Interdiscip Rev RNA. 2012; 3:145-58.

39. Sutthangkul J, Amparyup P, Charoensapsri W, Senapin S, Phiwsaiya K, Tassanakajon A. Suppression of shrimp melanization during white spot syndrome virus infection. J Biol Chem. 2015; 290:6470-81.

40. Thammasorn T, Sangsuriya P, Meemetta W, Senapin S, Jitrakorn S, Rattanarojpong T, Saksmerprome V. Largescale production and antiviral efficacy of multi-target double-stranded RNA for the prevention of white spot syndrome virus (WSSV) in shrimp. BMC Biotechnol. 2015; $15: 110$.
41. Hou F, Liu T, Wang Q, Liu Y, Sun C, Liu X. Identification and characterization of two Croquemort homologues in penaeid shrimp Litopenaeus vannamei. Fish Shellfish Immunol. 2017; 60:1-5.

42. Moon JS, Lee SH, Kim EJ, Cho H, Lee W, Kim GW, Park HJ, Cho SW, Lee C, Oh JW. Inhibition of hepatitis C virus in mice by a small interfering RNA targeting a highly conserved sequence in viral IRES pseudoknot. PLoS One. 2016; 11:e0146710.

43. Song H, Fang X, Jin L, Shaw GX, Wang YX, Ji X. The Functional Cycle of Rntlp: Five Consecutive Steps of Double-Stranded RNA Processing by a Eukaryotic RNase III. Structure. 2017; 25:353-63.

44. Zhi E, Li P, Chen H, Xu P, Zhu X, Zhu Z, He Z, Li Z. Decreased Expression of KIFC1 in Human Testes with Globozoospermic Defects. Genes (Basel). 2016; 7:75.

45. Kim N, Song K. KIFC1 is essential for bipolar spindle formation and genomic stability in the primary human fibroblast IMR-90 cell. Cell Struct Funct. 2013; 38:21-30.

46. Kushida Y, Takaine M, Nakano K, Sugai T, Vasudevan KK, Guha M, Jiang YY, Gaertig J, Numata O. Kinesin-14 is Important for Chromosome Segregation During Mitosis and Meiosis in the Ciliate Tetrahymena thermophila. J Eukaryot Microbiol. 2017; 64:293-307.

47. Higgins DM, Nannas NJ, Dawe RK. The Maize Divergent spindle-1 (dv1) gene encodes a Kinesin-14A motor protein required for meiotic spindle pole organization. Front Plant Sci. 2016; 7:1277.

48. Helmprobst F, Lillesaar C, Stigloher C. Expression of sept3, sept5a and sept5b in the Developing and Adult Nervous System of the Zebrafish (Danio rerio). Front Neuroanat. 2017; 11:6. 